\title{
Introducing the VIPLAN Methodology (with VSM) for Handling Messy Situations - Nine Lessons
}

\section{Stephen Harwood ${ }^{1}$ (D)}

Accepted: 11 September 2020 / Published online: 27 October 2020

(C) The Author(s) 2020

\begin{abstract}
This paper examines the utility of a novel and relatively unknown approach to handling messy situations. This approach, developed by Raul Espejo, is the VIPLAN Methodology. It is presented as a heuristic and comprises a set of six activities which act as 'pointers' to guide thinking and actions. The methodology's contribution rests upon its explicit focus upon the context within which messy situations are handled. This draws attention to the cybernetics of the situation (Cybernetic Loop), which can be made sense of using the Viable System Model. However, one of the challenges of the methodology is the perception that it is complex and difficult to use. A case-study is used to investigate how the methodology can be operationalised. This reveals a set of nine lessons, which are offered as guidelines to enhance our understanding of how to use the VIPLAN Methodology.
\end{abstract}

Keywords Problem structuring · PSM · VIPLAN methodology · Cybernetics · VSM $\cdot$ Systems thinking

\section{Introduction}

This paper explores a relatively unknown approach to the handling of messy situations - the VIPLAN Methodology. The Methodology is presented as a heuristic that guides our actions during the process of making sense of and engaging with a situation. This allows us to structure our thinking and actions in a way that permits us to be more questioning about what we are doing and who we are engaging with. Thus, this paper will appeal to those who are faced with the handling of messy situations.

Messy situations and their handling have been with us from immemorial times. However, it is more recently that scholarly attention has been given to how people approach these situations. For example, Dewey (1938) proposed his theory of inquiry which explained how

Stephen Harwood

stephen.harwood@ed.ac.uk 
people deal with unease about problem situations. In 1958, Simon and Newell discussed the 'ill-structured' nature of problem situations, viewing problem solving as information processing, rather than as a cognitive act (e.g. Duncker and Lees 1945; Getzels 1975, 1979). Within Operational Research (OR) Ackoff (1974) invited a rethink about how to deal with these 'messy' situations. One family of approaches pragmatically did emerge within OR (Mingers and Rosenhead 2004), this labelled Problem Structuring Methods (PSMs) by Rosenhead (1989). Common to these, is their emphasis on bringing forth an understanding of situations as perceived by different viewpoints. The emphasis is upon learning, but with a view to pragmatic consequences (Mingers and Rosenhead 2004).

One issue with such approaches concerns how the conditions for learning are created and maintained for the handling of the situation. For example, who are the stakeholders and how are they organised so that respective viewpoints can be expressed, outcomes negotiated and actions implemented. This draws attention to the organisational context within which a situation is made explicit, evaluated and negotiated. This is important because the structural aspects of how a situation is addressed, shapes what is addressed and the consequent outcomes. In other words, for example, if the wrong people are involved in dealing with a situation or there are poor communications, then the situation is unlikely to be appropriately diagnosed and handled, with the consequence of ongoing dissatisfaction of those affected by the situation.

One PSM that explicitly focuses attention upon this organisational context is the VIPLAN Methodology (Espejo 1988, 1992), (see Appendix for a discussion of why VIPLAN is a PSM approach). The VIPLAN Methodology not only addresses the learning process that deals with the experienced problem situation, but also explicitly gives attention to the analysis and design of the conditions within which the problem is established and handled. 'Closure' comes about with the easing of our unease about our understanding of and/or our action relating to the situation (Peirce 1873; Dewey 1938; March and Simon 1958; Ackoff and Emery 1972). However, a major drawback of the limited publications discussing the VIPLAN Methodology is a lack of detail explaining how the methodology can be operationalized.

This paper examines how the VIPLAN Methodology can be used to handle complex problem situations. It is grounded in a case-study to derive important insights about usage. The case-study is a messy multidisciplinary research project fraught with problems, during which the VIPLAN Methodology was used.

The paper commences with a brief outline of how complex problems are handled, focusing specifically upon Operational Research approaches. This is followed by an account of the VIPLAN Methodology. The case-study is then presented, which commences with an overview of the approach underpinning it, a description of both the problem situation and how it developed over time, then an assessment of the situation through the lens of the VIPLAN Methodology. The subsequent discussion evaluates the findings and offers nine lessons about use. The paper concludes that the VIPLAN Methodology offers a valuable contribution to the PSM portfolio, due to the attention it gives to the structural aspects of messy situations, this shaping how any problem situation can be handled and the consequent outcomes.

\section{Dealing with Problem Situations}

For some decades now, various domains have given scholarly attention to solving problems. Peirce's (1873, 1903) pragmatism and Dewey's (1938) theory of inquiry provided early 
explanations about how we deal with our unease in problem situations. In addition, one major stream of study has emerged in psychology, which has viewed problem solving as a cognitive act. This work is grounded in Experimental Psychology (e.g. Duncker and Lees 1945), in particular in German speaking countries, though research has tended to focus upon simple laboratory studies (Buchner 1995). Newell and Simon's (1972) 'Human Problem Solving' presented the view of the individual as a 'processor of information'. Indeed, Newell et al. (1958) argued that any description of how to solve problems should itself be capable of enabling problem solving. Furthermore, there is the view that better formulated problems lead to better solutions (Getzels 1975; Watson 1976). However, problems range broadly from puzzles, to well-structured problems, to ill-structured problems (Jonassen 1997). Of these, it is the ill-structured problems that are most problematical due to their complexity, uncertainty and turbulence over time. Since ill-structured problems arise in all facets of life, this has led to many studies in different domains, for example in psychology (e.g. Frensch and Funke 1995; Stadler et al. 2019), design thinking (Goel and Pirolli 1992; Buchanan 1992; Conklin 2006; Brown 2008; Kolko 2015; Micheli et al. 2019), instructional design (Jonassen 1997, 2000; McDonald and Yanchar 2020), project management (Ahern et al. 2014; Mikkelsen 2020), business decision-making (Snowden 2002; Kaye et al. 2020) and engineering education (Dringenberg and Purzer 2018; Wolff 2020).

It is to the Operational Research (OR) domain that our attention turns, as it has its own welldeveloped tradition for the pragmatic handling of problems, in particular, ill-structured problems (Ranyard 1995; Mingers and Rosenhead 2004). In contrast to design thinking with its focus upon artefacts, the OR orientation is more orientated to issues of organisation and how that can be improved (e.g. logistics, production, social problems).

\section{The Nature of a Problem Through the OR Lens}

One of the more fundamental questions that has appeared within the OR domain concerns the nature of a problem and how it is handled. Ackoff and Emery (1972) draw attention to the cognitive state of dissatisfaction and doubt about what to do, in how they define a problem:

A purposeful state that a purposeful individual is dissatisfied with, and in which he is doubtful about which of the available courses of action will change that state to a satisfactory one (Ackoff and Emery 1972: 108).

This is reminiscent of March and Simon (1958), for whom the aim of decision-making is mainly to satisfy. Ackoff and Emery (1972) state that 'disposing' of a problem can be achieved in one of three ways. The first, dissolution, can be achieved by changing intentions, thereby dissolving dissatisfaction. Alternatively, the act of making an 'arbitrary choice' can give rise to action that may be successful in removing dissatisfaction. The third, solving the problem, involves inquiry to establish the possibilities (alternatives) for action that provide solutions, from which one is selected that is expected to most likely to produce satisfaction. Eden (1987) offers the view that problems are not so much about their solving, but 'finishing':

Problem-finishing as a descriptive concept is useful to the extent to which we recognize that the practicalities of getting things done are a part of how the problem is defined (Eden 1987:103).

This reflects the Western culture view of a problem having an end point that denotes its completion, a view attributed to the educational system in which problems are well structured, 
singular, abstract and have right answers, obviating the issues of negotiation, emotion or tensions (Eden 1987).

\section{How a Problem is Defined Through the OR Lens}

A second question concerns how a problem is defined. This introduces the problem structuring lens which has emerged within OR, particularly in the UK. It was recognised that there are many situations where a problem is unclear and/or that there are different views as to what constitutes the problem. These problems are not unitary defined, well-structured and with 'one best way' of solving them (Rosenhead 1989). Instead, there is a need to hear the multiple perspectives about the situation and identify and negotiate the problem before any attempt is made to think about a solution (Ackermann 2012). These types of problem situations have been labelled wicked (Churchman 1967; Rittel and Webber 1973), messy (Ackoff 1974) and fuzzy (Zadeh 1965).

This has led to the emergence in the late 1970s of Soft OR and, specifically, the domain of techniques, labelled by Rosenhead (1989) as Problem Structuring Methods (PSMs), to deal with these particular forms of problem situation (Ackermann 2012). PSMs have developed pragmatically, with their theoretical conceptualisation following later (Mingers and Rosenhead 2004). Prominent examples of PSMs are Soft Systems Methodology (SSM) (Checkland 1972, 1981), Strategic Choice Approach (SCA) (Friend and Hickling 1987; Friend 1989) and Strategic Options Development and Analysis (SODA) (Eden 1988, 1994; Eden and Ackermann 2001). However, PSMs have been critiqued for a lack of definition as to what they are, a lack of consistency and rigour in use, their inability to provide a 'single right answer', a lack of evidence of effectiveness and their difficulty to teach (Ackermann 2012). In addition, PSMs have been criticised for their apparent stagnation in their development within academia, amidst notions that the development of PSM skills are difficult, that the wider OR community has not bought-into PSMs and that the PSM community is small, though active (Morrill 2007). Nevertheless, there is still activity with more recent developments relating to the evaluation of PSMs (Midgley et al. 2013; Lami and Tavella 2019), the characterisation of PSMs (Smith and Shaw 2019) and application in Community OR (Johnson et al. 2018), with Behavioural OR examining how people engage with OR methods to support problem solving (Hämäläinen et al. 2013; Kunc et al. 2016; Franco and Hämäläinen 2016; White et al. 2020). Other developments include those of practitioners, but these tend not to be written formally for wider consumption (Morrill 2007).

Amongst the aforementioned PSMs, the Soft Systems Methodology offers one well-known approach for the transformation of an ill-defined problem situation into agreed action to deal with the situation (Munro and Mingers 2002; Mingers and White 2010). An empirically grounded approach for the handling of messes, it was introduced in Checkland (1972), detailed in Checkland (1981) and reflected upon in Checkland (1999). It is still receiving scholarly attention as illustrated with Paucar-Caceres and Jerardino-Wiesenborn (2020) and RamírezGutiérrez et al. (2020). The SSM focuses attention upon the learning aspects of the process of making sense of messes in such a way as to give rise to agreed change (Checkland 1972). Firstly, this involves finding out about and expressing the situation - creating a rich picture. Then this leads to concise statements (root definitions) about possible outcome states in terms of relevant 'human activity systems', which are conceptually modelled and used to evaluate possible changes. 


\section{The VIPLAN Methodology}

In contrast, a more recent, yet relatively unknown approach is the VIPLAN Methodology. It was specifically developed by Espejo (1988) to handle messy situations. As with the handling of any problem situation, learning is a key activity, this taking place in a Learning Loop. However, learning is shaped by the context within which it takes place and, thus, by both its constituent participants, whose views inform, as well as those not participating, whose views are excluded. This draws attention to the distinctive feature of the methodology, which is the explicit attention given to this context within which learning takes place (Cybernetic Loop). The aim is to create contextual conditions that are more conducive for learning to take place. Since this is about the enrolment and organisation of those who participate in dealing with the situation, this is a structural issue in contrast to the content of conversations that is given emphasis in the Learning Loop.

\section{Historical Development}

The VIPLAN Methodology was originally presented by Raul Espejo (1988) as the Cybernetic Methodology and taught on the Aston University MBA course on 'Problem Solving' in the 1980s. It was renamed in Bowling and Espejo (2000). It was developed in conjunction with the VIPLAN Method, an approach for handling Stafford Beer's Viable System Model [VSM] (Beer 1972, 1979, 1984, 1985; Espejo and Harnden 1989). VIPLAN stands for Viability Planning (Espejo 2011a). The VIPLAN Methodology has subsequently appeared in publications on a number of occasions (Espejo 1990, 1991, 1992, 2015a, b; Bowling and Espejo 1992, 2000; Espejo et al. 1996; Espejo and Reyes 2011). However, only a few provide an insight into the application of the methodology (Bowling and Espejo 1992; Espejo and Reyes 2011; Perko and Espejo 2017). Whilst Bowling and Espejo (2000) and Perko and Espejo (2017) make reference to the VIPLAN Methodology in their studies of a retail bank and Big Data Analytics respectively, there is little explanation as to how it is used.

The VIPLAN Methodology is depicted in Fig. 1. Whilst the methodology draws from the Soft Systems Methodology, evidenced most clearly in activities \#1 (rich picture) and \#2 (names), the methodology is conceptually grounded in second order cybernetics (Von Foester 1979). First order cybernetics is concerned with that which is the object of our attention, giving rise to the view of cybernetics as being positivistic and conducive to the approaches of science. However, as humans, we are all observers of that within which we engage and, though our observations, engage with others in the everyday of living and dealing with disturbances. The conversations that are possible are those that result from our engagement with each other. If there is no channel of engagement, whether face-to-face or digitally over distance, then conversations cannot occur. Moreover, the richness of the conversations depends upon who is included / excluded and the nature of the organization of these viewpoints. This draws attention to the cybernetics of the situation in terms of how conversations are managed. If it is effective then the requisite content, in terms of issues relevant to the situation, is more likely to manifest. This disposition to social phenomena shifts the ontological - epistemological position to one associated with constructivism - interpretivism. Moreover, as an approach for handling messy situations, it meets the criteria of a PSM established by Rosenhead (1989) and Smith and Shaw (2019) (see Appendix), and thus, the VIPLAN Methodology is argued to be a PSM. 


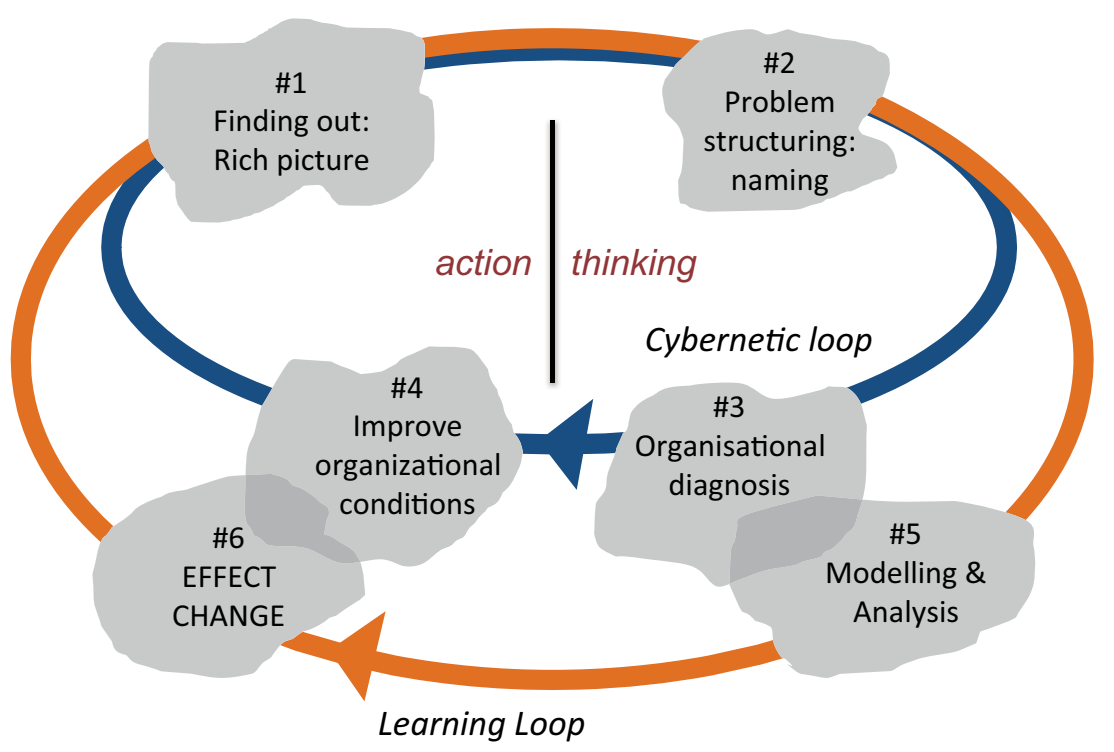

Fig. 1 The VIPLAN Methodology (adapted from Espejo 1988, 1992; Bowling and Espejo 2000)

\section{Initial Elaboration}

As previously stated, the methodology was originally presented in Espejo (1988) and elaborated upon in Espejo (1990, 1991, 1992). Whilst Bowling and Espejo (2000) develop this insight into the methodology, they provide limited elaboration. The methodology, as shown in Fig. 1, comprises six activities (denoted by the hash). These are connected by two loops, the inner Cybernetic Loop connecting activities \#3 and \#4, and the Learning Loop connecting activities \#5 and \#6. These two loops denote, respectively, the operational and informational domains of the situation. The operational domain is the realm of activity, interactions and governance, with emphasis upon the mechanisms of communications, where a mechanism is defined as an observed invariance in the dynamics of the operational domain (Harwood 2011). The informational domain is the realm of meaning, with emphasis upon the content of communications. In practice they are intertwined. Moreover, the left hand side pertains to real world engagement (action), whilst the right side relates to the abstract world of conceptualisation (thinking), though in practice, this is also intertwined.

Application can be both diagnostic and design. Moreover, it can support both individual and group learning (Espejo et al. 1996). The emphasis is upon improving the organisational context for more effective learning. In the case when groups lack a common purpose, effort may focus upon how common purpose can be created in the form of both an identity and a group structure. Alternatively, learning will be constrained and more orientated towards individual learning (Espejo et al. 1996).

Activity \#1 is a the generation of a rich picture. This is about finding out about the situation in order to reveal the multiple ways it can be viewed. The emphasis is upon expression. The notion of a rich picture was developed by Peter Checkland in the Soft Systems Methodology as a means to appreciate a situation that is viewed as problematic (Checkland 1972, 1981). The challenge of producing and using rich pictures has been elucidated by Lewis (1992), Bronte- 
Stewart (1999), Bell and Morse (2013) and Bell et al. (2019), who highlight their informal expressive utility.

Activity \#2 uses the rich picture to structure the situation in terms of names. Following Checkland (1981), these names are concise structured descriptions or root definitions defining the problem and / or a desired outcome. They identify the systems invoked by the names. The emphasis is upon purpose and is revealed in the verb used to express the change. Names can be evaluated for consistency using the mnemonics CATWOE (Checkland 1981) and TASCOI (Espejo 1988; Espejo et al. 1999). These identify the transformation implied by the purpose and the stakeholders (Fig. 2, Table 1). TASCOI focuses attention upon the appropriate organizational systems for the name with the aim to name the relevant organisational systems. CATWOE is orientated to exploring possibilities which requires that ' $\mathrm{W}$ ' is made explicit, i.e. this perspective is inherent in the "name. Two classes of names are identified. The first, issue based names, relate to the issues that can be and / or are addressed. The second, organisational system based names, pertains to the relevant organizational system (i.e. context) within which problem handling is to take place, this identifying the necessary stakeholders. This second name is significant as it identifies, not necessarily a formal organisational entity, but possibly the hybrid organisation of agents from formal organisational entities that create the appropriate context for learning. Irrespective of which mnemonic is used, \#2 marks the transition from uncertainty to the clear bounding of the focus of attention.

The following two activities (\#3 and \#4) are related to the Cybernetic Loop and the creation of organizational conditions more conducive for handling the problem. This structural aspect of the problem domain recognises that the nature of the content of communications is shaped by who is present / absent.

Activity \#3 examines the organizational context identified by the name and, thus, how identified stakeholders can be better organized to improve communications. This is a modelling activity, with the Viable System Model (VSM) (Beer 1979, 1985; Espejo and Harnden 1989) offering an appropriate epistemological device (Espejo 1992, 1996) to support conversations about organizational improvements. The VSM helps to make sense of the manner in which people are or can be organised with regard to both communication and activity.

Activity \#4 is the action of creating a more conducive organizational context for dealing with the problem situation within the Learning Loop, drawing upon the insights from \#3.

Activities \#5 and \#6 relate to the Learning Loop. This is concerned with the content of conversations and the associated learning with view to closure relative to the agreed problem. These activities, together with \#1 and \#2, constitute the more conventional view of the inquiry process (e.g. Dewey 1938; Checkland 1981). It assumes that activities \#3 and \#4 have been productive in creating conditions conducive for more effective conversations.

\section{CATWOE}

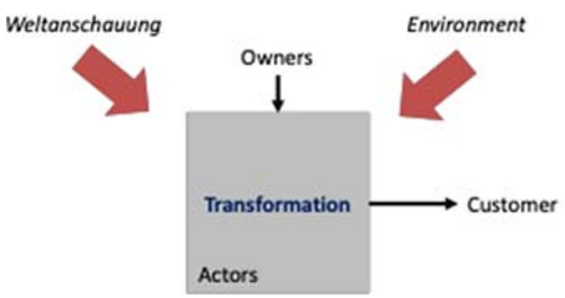

TASCOI

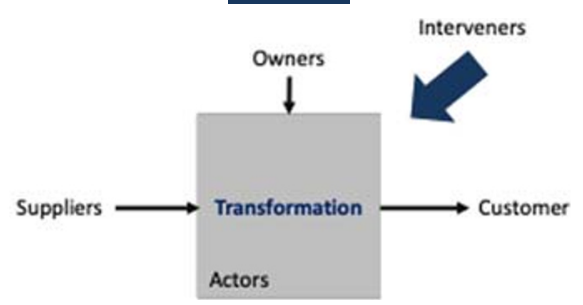

Fig. 2 CATWOE and TASCOI in terms of a Transformation of a Black Box 


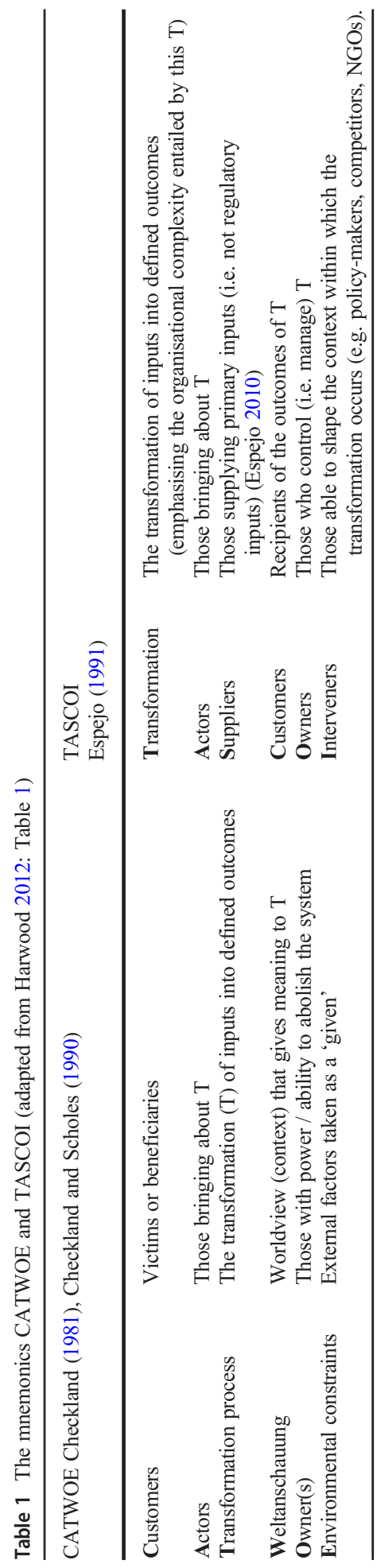


Activity \#5, like \#3, is a modelling activity. A model is viewed in the broadest of meanings (c.f. Pidd 2003). Models can be conceptual (i.e. logically coherent) or descriptive representations of reality. Alternatively, models can be viewed as epistemological devices to elicit views and develop appreciations about situations as well as explore possible solutions (Espejo 1992, 1996). Though articulation, new distinctions can emerge. The aim is not sophistication nor accuracy. Moreover, they should not constrain the emergence of possibilities. Their value is in their usefulness (Wilson 1984; Beer 1985). Thus, modelling can take any form, but with the aim to enrich both the appreciation of the situation and the problem (Espejo and Reyes 2011).

Activity \#6 is the action resulting from decisions arising from \#5. It gives rise to closure. However, this is not an end in itself, but, upon closure, serves as a transition to the next problem situation requiring attention.

In terms of how the methodology is to be used, Espejo and Reyes (2011) argue that the VIPLAN Methodology is a heuristic for learning, rather than a formalised framework for problem solving. In other words, it is not to be expected that the activities are followed sequentially. Instead, activities serve as 'pointers' for thinking appropriately about what is happening, invoking flexibility in application.

\section{Influence of Kim (1993)}

One development of the VIPLAN Methodology is its framing by Espejo et al. (1996) in the language of the organisational learning cycle developed by Kim (1993), which Kim attributes to Kofman (1992). This cycle comprises four activities captured by the mnemonic, OADI. People Observe [O] what is happening, then reflectively Assess [A] their experience from which they conceptually Design [D] an appropriate response, which is tested through its Implementation [I]. Observe relates to \#1, Assess to \#2, Design to \#3 and \#5, and Implementation to \#4 and \#6. This mnemonic reappears in Espejo and Reyes (2011), Espejo (2015a) and Perko and Espejo (2017). While Kolb (1981) was concerned with the cognitive learning styles of individual learners that resulted in the development of 'Experiential Learning Theory' (ELT), Kim drew attention to the organisational aspects of learning, in particular, the notion of the 'organisation's memory' (e.g. shared mental models).

This organisational learning perspective is iterated in Espejo (2015a), though the language used is slightly different to the other presentations of the methodology. For example, \#2, whilst labelled 'Assessing', is described as 'what do these observations mean to actors and agents'. Likewise the Cybernetic Loop is renamed the 'second order learning loop' to denote the learning associated with self-organisation and the development of 'dynamic capability and potentiality'. Whilst the language is different, the underlying meaning appears to be retained, though is perhaps not as explicitly clear as in other versions. This version of the VIPLAN Methodology reappears in Perko and Espejo (2017).

A variant of this appears in Espejo (2015b), in which the VIPLAN Methodology is presented as a learning platform, with \#2 labelled Appreciation and \#3 / \#5 being both Assess and Design. The Cybernetic Loop (described as a Diagnostic and Improvement Loop) is about improving the organisational adaptation mechanism and hence its capability to handle what is going on. The Learning Loop (referred to as the Enterprise Development Loop) relates to the organisation's strategies. 


\section{Applications}

There appear to be only a few published applications of how the VIPLAN Methodology has been used, these associated with Espejo and Harwood. One can speculate as to why this is the case, but it is postulated that this is due to general lack of awareness and understanding of the methodology, possibly owing to the relative obscurity of where it has been published as well as lack of clarity about how to operationalise it.

One of the most comprehensive applications of the VIPLAN Methodology was Espejo's work (1995 to 1998) with the National Audit Office of Colombia (Espejo 2019). This specific application led to the introduction of second-order auditing as one of the auditing tools available to the auditors of the National Audit Office, thereby increasing the opportunities for the self-regulation of the affected institutions. Reyes (2001) provides an insight into the learning associated with the development of these second-order auditing practices, whilst Urdaneta (2001) reveals how the different training phases were organised, thus facilitating the learning experiences. Both draw upon the VSM to enable thinking about both the audit practices and their organisation.

The second is a case-study entitled 'Regent Engineering' (Bowling and Espejo 1992). This study was concerned with issues relating to customer satisfaction and delivery as well as product quality in an engineering company. Activity \#1 involved interviews, meetings and informal discussions. During \#2, it was recognised that attention needed to focus on only one part of the organisation. This led to an evaluation of that part of the organisation using the VSM, which resulted in the setting up of regular morning meetings of key personnel to overcome a communication issue. Descriptive process models (\#5) provided insights into the issues, thus revealing possibilities for change, but also highlighting the issue of interpersonal problems and the need for individuals to change. Change that was both culturally acceptable and organisationally feasible was implemented (\#6) through workshops, leading to an improvement in personal relations. An update to this case was provided in Espejo (2011b). This update reveals the structural issues that underpinned the problems experienced by the company and explains the role of structure in determining what happens within organisations. It highlights the importance of the operational domain in shaping what transpires in the informational domain.

A third case-study is that of Swedish Nuclear Regulators (Espejo and Reyes 2011). This is a complex study into nuclear waste management that draws upon interviews, meetings and workshops. One identified concern was the transparency of policy decisions. The unfolding process of inquiry revealed the braiding of the cybernetic and learning loops, drawing upon the VSM to explore possibilities.

The other accounts of the VIPLAN Methodology are by Harwood. The first is its application to the management of change in a production operation (Harwood 2012). Subsequent applications are to the development of a research methods course (Harwood 2016), as well as its use to make sense of the PhD experience (Harwood and Eaves 2018). Further, it has been offered as an holistic approach for handling Water-Energy-Food Nexus issues (Harwood 2018), as well as is argued to provide a problem orientated methodological approach within which to use Stafford Beer's Viable System Model (Harwood 2019). However, as mentioned, one major limitation of all these studies is the lack of detail about how the methodology can be operationalized. 


\section{Commentary}

The VIPLAN Methodology has evolved conceptually over time, being grounded more deeply into the dynamics of organisational adaptation with the incorporation of Kim's (1993) work on organisational learning. Through this understanding of the concept of organisational leaning, then this can be used to improve the organisational context in which leaning takes place (i.e. the handling of messy situations), with the expectation that this will result in more effective handling of the situation.

However, despite the various conceptual and applied accounts that explain the VIPLAN Methodology, the lack of guidelines about how to operationalise the VIPLAN Methodology invites a variety of questions. For example, in what mode can it be used: does it solely prescribe how to handle a problem situation or are there other ways to use the methodology? Indeed, is it a prescriptive methodology? How would one characterise this methodology? In what organisational context(s) should it be used? Is it to be used in a group situation and, if so, how? Does everyone need to understand the methodology in its use, or is it a methodology that is tacitly used by a facilitator to take participants through a self-discovery journey, or is it both? How are conflicting views to be resolved? Are the same people involved in all activities or will these change from activity to activity? How are these people to be identified and also enrolled into these activities? Who generates the rich picture (\#1) and how does it translate into both issue and organisational system names (\#2)? How are names to be generated and agreed? Can quantitative modelling be equally incorporated into the implied qualitative modelling activities of \#3 and \#5? What happens if it is not possible to create the organisational conditions (\#4) that are modelled in \#3? How is the effectiveness of change (\#6) to be assessed?

Most of these questions relate to the organisational context within which the methodology is used. Since it has been earlier argued that the VIPLAN Methodology is a PSM, and others have indicated that PSMs tend to take place in workshop environments (Mingers and Rosenhead 2004; Lami and Tavella 2019), then is a workshop application the only context of application? A workshop suggests an event over a very short duration (e.g. a day), but is the methodology appropriate for a study over a much longer time (e.g. a year)? For example, completing a PhD takes about three years if not a lot longer and is a complex unfolding process involving a variety of activities (Harwood and Eaves 2018). When the top level generic approach to inquiry is unpacked recursively to reveal the tasks specific to each stage of the $\mathrm{PhD}$ experience, this reveals a complex of tasks, for each of which there is a corresponding organisational context. For example, \#3 is a modelling activity which belongs to the cybernetic loop, but it, itself, has cybernetic considerations. This modelling can be carried out in a group as a one-off activity or it may be the result of ongoing discussions amongst participants over time. Thus, the complexity of dealing with any specific named problem is magnified when consideration is given to the cybernetics of each activity that collectively constitutes the approach to dealing with the problem. Moreover, this named problem may change over time as an outcome of subsequent activities associated with the VIPLAN Methodology. This complexity raises potential confusion, which invites the question of how this confusion can be mitigated. It is during our reflections about what is happening in our intervention that it becomes useful to map out the complex set of activities, interactions and events associated with how the problem is being handled, in order to understand and evaluate what is happening. 
Table 2 Questions about use of the VIPLAN methodology

$\begin{array}{ll}\text { Theme } & \text { QUESTIONS }\end{array}$

1. Mode of use

2. A temporal dimension

3. Organisational context (system)

4. Organising for use

5. Making sense of the situation (\#1)

6. Defining the problem (\#2)

7. Modelling (\#3/\#5) [thinking]

8. Managing change happen (\#4/\#6) [action]

9. Reflecting over what is happening
In what mode can it be used: does it solely prescribe how to handle a situation or are there other ways to use the methodology? Indeed is it a prescriptive methodology?

How would one characterise this methodology?

Is its use for a one off activity (e.g. workshop based) or is it for ongoing activity over time (e.g. $\mathrm{PhD}$ )

In what organisational context(s) should it be used?

Is it to be used in a group situation and, if so, how?

Does everyone need to understand the methodology in its use or is it a methodology that is tacitly used by a facilitator to take participants through a self-discovery journey or is it both?

How are conflicting views to be resolved?

Are the same people involved in all activities or will these change from activity to activity?

How are these people to be identified and also enrolled into these activities?

Who generates the rich picture (\#1) and how does it translate into both issue and organisational system names (\#2)?

How are names to be generated and agreed?

Can quantitative modelling be equally incorporated to the implied qualitative modelling activities of \#3 and \#5?

What happens if it is not possible to create the organisational conditions (\#4) that are modelled in \#3?

How is the effectiveness of change (\#6) to be assessed?

How does one map out the complex set of activities, interactions and events to handle a messy situation in order to make sense of and reflect over what is happening?

However, this invites the question of how can this mapping be carried out in a meaningful way.

These preceding questions are summarised in Table 2 and categorised into themes for later discussion. The methodology, with its apparent simplicity, when applied to a messy situation, unpacks to reveal its own potential complexity. This is perhaps explained by Ashby's Law of Requisite Variety: "only variety in R can force down the variety due to D..." (Ashby: 1956: 207). The variety (D) of a mess requires the requisite variety (R) to handle it. Nevertheless, in light of this evaluation there is still the challenge of how the VIPLAN Methodology can be used in a practical way.

Table 3 Analysing the case-study

\begin{tabular}{ll}
\hline Stage & Focus of analysis \\
\hline 1 & What happened - the events \\
2 & How events are made sense of by using the VIPLAN Methodology \\
3 & How use of the VIPLAN Methodology can be better \\
& understood through its use to make sense of events \\
\hline
\end{tabular}




\section{Approach to the Case-Study}

To explore the operationalisation of the VIPLAN Methodology, the handling of a messy situation in which the VIPLAN Methodology was discovered to be helpful, is presented as a case-study. Whilst it does not answer all the preceding questions, it does contribute towards a deeper understand of how the methodology can be used. Further, this case-study is one of the few studies about the experience of doing research, an issue raised by Franco and Greiffenhagen (2018) about the 'real time doing' that constitutes the practice of OR.

This is a longitudinal case-study of a messy multi-disciplinary research project that took place over three years in an Higher Education Institution (HEI) to develop and implement a technology for use in an industrial production facility. It involved a number of academics of varying experience from two separate Schools. The focus of this case-study is the evaluation of a researcher's two year experience as a member of this research project, which the researcher joined over one year into the project. The problem faced was to clarify the role of the researcher, which became unclear due to the failure to implement the technology in the operational context that the researcher was to investigate. The VIPLAN Methodology provided a means to rationalise the complexity of the project, communicate more clearly what was happening and establish focus. More importantly, it allowed doubt to be removed and established legitimacy in terms of research purpose. Prior to the use of the methodology, the researcher was fumbling around trying to understand what was going on, producing increasingly sophisticated proposals (models) of the multiple dimensions that surfaced, with unclear purpose.

Using the concept of observing the observing system and drawing upon the notion of second order cybernetics (Von Foester 1979), the case-study analysis is presented in three stages (Table 3). The first stage is a description of what happened. The second stage is an evaluation of the problematic situation through the lens of a researcher involved in a multidisciplinary project. This is an ethnographic reflective analysis of the researcher's experience, which includes an evaluation of the situation through the lens of the VIPLAN Methodology. Stage three is an evaluation from the perspective of an observer, of this case-study and the use of the VIPLAN Methodology to deal with the situation, in order to explore what can be learnt about the VIPLAN methodology in use. So as to preserve the anonymity of participants, the specific details of the study are omitted.

\section{Stages 1, 2: An Ethnographic Study - Discovering the VIPLAN Methodology}

This case-study is grounded in the researcher's ethnographic reflective analysis of the experience of establishing purpose and research focus. As the project progressed, it became evident that the project itself would become an object of the researcher's attention, which had the consent of the project's participants. In the process of trying to make sense of the project, it was fourteen months into the project when the researcher realised that the VIPLAN Methodology provided a means to make sense of the situation. This delay in recognising the VIPLAN Methodology is perhaps symptomatic of myopic thinking (Levinthal and March 1993), with lock-in to a particular way of thinking, influenced by those in proximity. 
Over this period, in keeping with good research practice, the researcher kept a detailed log of the experience (Nadin and Cassell 2006), capturing activities, interactions, events and personal thoughts. Latterly, the log together with related materials (e.g. notes from conversations and meetings, emails, newsletters) were chronologically mapped to the VIPLAN Methodology in a table comprising three columns, the first relating to the situation and how it was defined (\#1 and \#2), the second to the observed system (\#5 and \#6), this being the object of study of the research project (i.e. the technology development), the third about the observing system (\#3 and \#4). This log table provided a framework to systematically evaluate the research situation in terms of the six activities of the VIPLAN Methodology. This evaluation allows the researcher's insights into the project to be shared through the lens of the VIPLAN Methodology.

\section{Stage 3: An Evaluation of the VIPLAN Methodology (Nine Lessons)}

The aim of this is to examine the evaluation (stage 2) of the application of the VIPLAN Methodology to establish what lessons can be learnt from it. The insights from this evaluation together with the extant literatures and the author's experience of the methodology are used to produce the nine lessons. These lessons are specific to the case. Thus, a different case may reveal a different set of lessons, yet contribute to a deepening understanding of how the Methodology can be used.

\section{Case-Study}

This case offers an insight into a messy situation arising from a research project that had deviated from its original intention. It is presented in a relatively abstract manner to maintain the anonymity of all those involved in the project. The important issue is that, as a research project fraught with problems, it affords a deeper appreciation of how the VIPLAN Methodology was recognised and used to handle the messy situation.

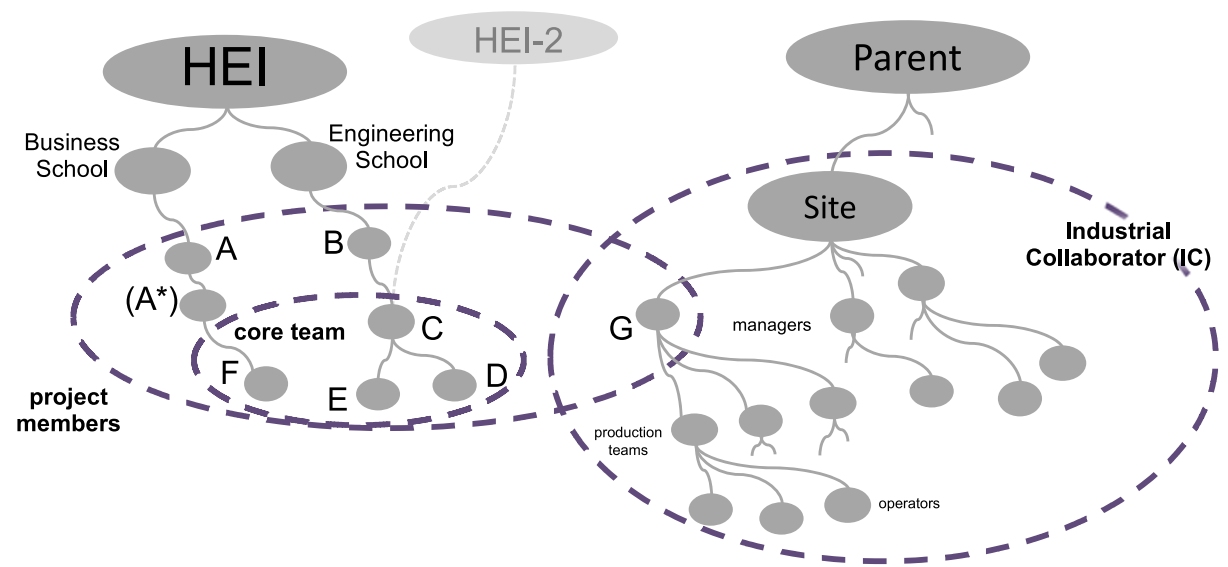

Fig. 3 Unfolding the complexity of the project from the perspective of organizational ownership (HEI: Higher Education Institution; Parent is the site's parent company) 


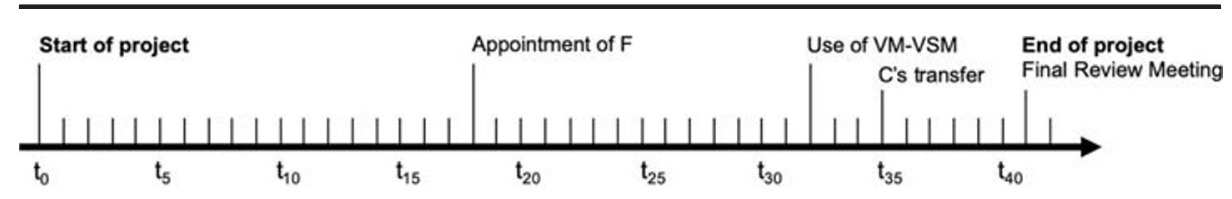

Fig. 4 Project timeline (months) drawing attention to three key events (VM: VIPLAN Methodology; VSM: Viable System Model)

\section{The Case Described (Stage 1)}

This provides an overview of the problem situation and key developments over time.

\section{The Problem Situation}

The case was a multidisciplinary research project that lasted three years and five months. The aim of the project was to develop and introduce an automated system into a collaborating industrial partner and examine the organizational implications. Thus, this was not just a technical project, but embraced a social element. It reflected the combined interests of three named Investigators, two located in an Engineering School (participants B and C in Fig. 3) with the third (A) located within a Business School. Further, when fully established, the core active team of four full-time members would comprise researchers from the disciplines of mechanical engineering $(C, D)$, computing $(E)$ and management $(F)$. F's appointment eighteen months into the project (Fig. 4) was based upon the assumption that the technical development by the others had progressed sufficiently for its implementation within the industrial collaborator (IC), thereby providing material for study by F.

However, early on, one of the Investigators (B) fell ill and withdrew, resulting in another (C), who was also one of the researchers involved in the technical development, assuming the lead. However, upon appointment, the management researcher $(\mathrm{F})$, rather than report to $\mathrm{C}$, reported to the Business School Investigator (A), who was actively interested in the project but, due to commitments, delegated this to interested colleagues $\left(\mathrm{A}^{*}\right)$.

Further, by the time of the F's appointment, whilst the project had made progress in terms of technical development, it was not ready for implementation in the industrial collaborator (IC). This created a dilemma. For those involved in the technical development (C, D, E) this was not a problem. There was ongoing progress, although it was unclear when there would be an implementation within the IC. Indeed, this lack of transparency about the implementation raised F's concerns fairly early on. This was because F's role was to study the implications of the implementation from a management perspective. For F, what started with a clearly defined contribution, quickly transformed into one of uncertainty and doubt. Over time, it became increasingly certain that there would be no implementation.

\section{The Project's Development over Time}

From a technical perspective, the project made progress. However, without an implementation there was no scope for management research and the associated agenda was not being met. Nevertheless, the IC provided an interesting case to understand its unique approach to manufacturing operations. Whilst this, to a degree, counteracted the uncertainty, alignment with the overall project was an ongoing issue, involving discussions and disagreement, breakdown in communications and the emergence of a refreshed focus. From F's perspective, 
the big challenge was to make sense of what was happening and establish purpose and scope for contribution to the project. However, one later disruption to the possibility of this, was C's move to another employer (HEI-2) a few months after final clarification of F's possible contribution.

\section{Discovery and Making Sense Though the Lens of the VIPLAN Methodology (Stage 2)}

A reading of the original project brief gave the impression of a well-designed and coherent project. It was to develop an innovative technology that was to be introduced into the workplace and its organizational impact to be evaluated. However, an observer would not be mistaken to subsequently discern two distinct trajectories in what happened (Fig. 6). One was the development of the technology, involving C, D and E, which made progress. The other related to the intended study of the implementation of this technology in a workplace context, which did not happen and raised the question of what F was to do. From F's perspective, the dilemma of what to study, in part, shifted from the project's object of study (the implementation of a technology) to the project itself becoming the object of study. F's challenge was a problem structuring matter. This was latterly facilitated by the VIPLAN Methodology, which drew attention to the cybernetics of the situation and how to make sense of it, this pertaining to the cybernetics loop of the VIPLAN Methodology. The focused attention upon the problem structuring aspect of the VIPLAN Methodology helped to explain what was being experienced. Finally, the sense-making process involved modelling, not only of what was the object of study of the project, but also of the project itself.

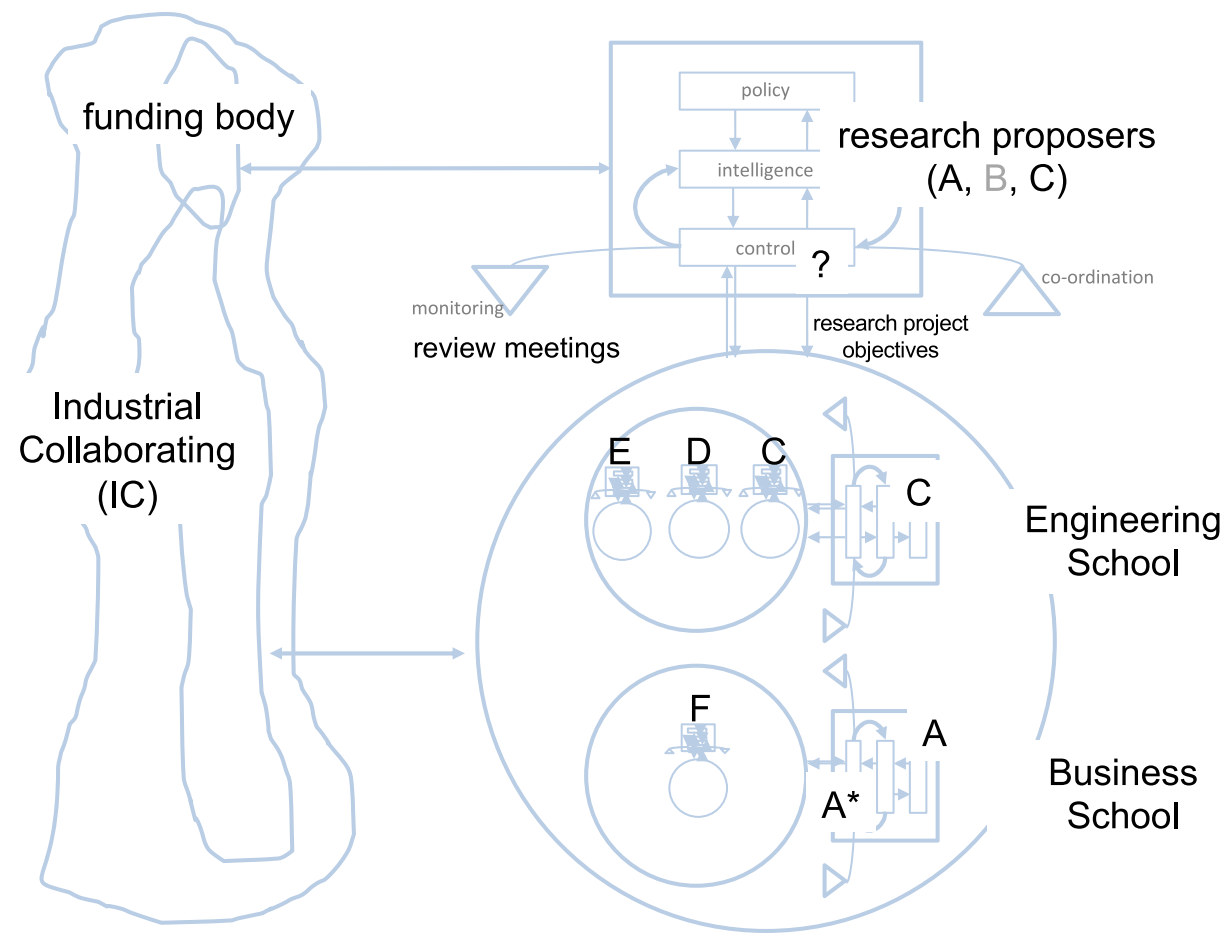

Fig. 5 The regulatory capacity of project participants to shape the direction of the project 


\section{Cybernetics of the Situation}

The cybernetics of the situation is implied in Fig. 3, but is more explicitly revealed in Fig. 5, which reflects an analysis conducted by $\mathrm{F}$ fourteen months into the project. This analysis through the lens of the VSM revealed the regulatory capacity of the actors within the project to shape what was happening and "the ineffectual nature of the regulatory mechanisms originally envisaged...". In other words, the project was dysfunctional in the actuality of how it was regulated, despite initial intentions.

In terms of what happened, the unfolding of the organizational complexity reveals the two HEI Schools and the IC. The project proposers are A, B and C, with B withdrawing at an early stage for health reasons. $\mathrm{C}$ recruited $\mathrm{D}$ and $\mathrm{E}$ at an early stage in the project to develop the 'automated system'. Eighteen months into the project (Fig. 4) researcher F was recruited by A, but because of A's work commitments, $F$ was directed by designates $\left(A^{*}\right)$, first one, then another from within the Business School, both of whom also had interests in the project. Whilst, C, D and E functioned as a coherent entity with the clear goal of technology development, led by $\mathrm{C}$, this had limited involvement from either $\mathrm{F}$ or individuals within the IC. There was little interest in the technical aspects of what was being developed. Nonetheless, the IC liaison, G, was very accessible and introduced project members to others within the IC. However, irrespective of the openness of people within the IC, there was limited collaboration on the problems of the IC. F's research about the IC was not used by the IC. Neither did the IC collate specific data requested for the project by $\mathrm{A} *$ that could be used by $\mathrm{F}$, since it was not a priority for the IC.

Moreover, the roles of $\mathrm{C}$ and $\mathrm{F}$ were unclear, manifesting in conflicting views as to the direction of the project. This was exacerbated by disagreements between $\mathrm{C}$ and $\mathrm{A} * \mathrm{~F}$ about how the organizational aspects of the project were to develop, particularly in the absence of any technology in the IC. Informal communications between F and C, D, E, broke down, reducing to emails and periodic memos, with intermittent meetings. These meetings tended to be informal events chaired by $\mathrm{C}$, with only few unable to attend on occasion. These were

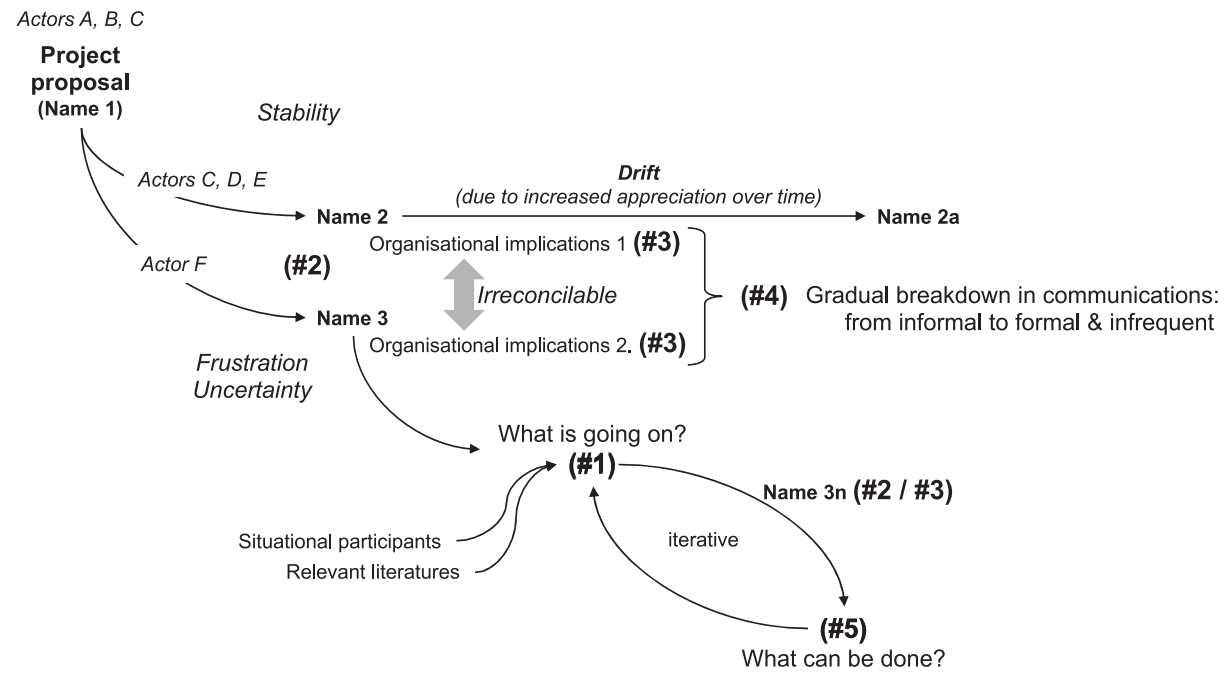

Fig. 6 Unpacking the project brief in terms of the activities (\#) of the VIPLAN Methodology 


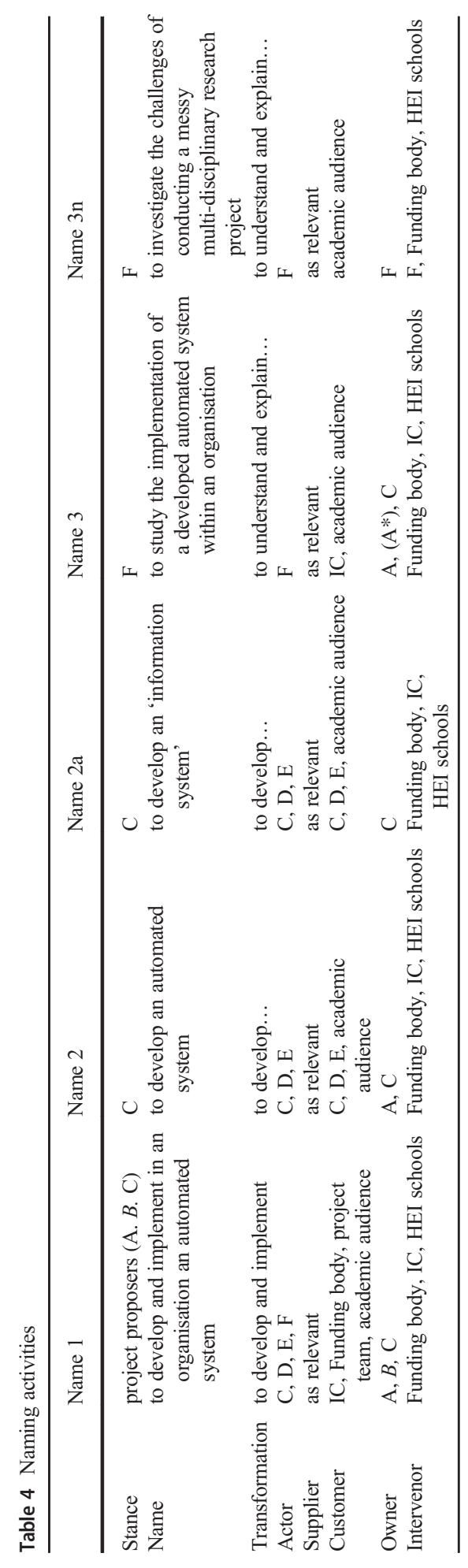


effectively discussions / disagreements about what was to happen with, only occasionally, minutes being circulated.

Furthermore, in the final year of the project, researchers started to think about post-project employment. Indeed, C transferred to another employer (HEI-2) six months before the end of the project (Fig. 4).

Over this period there were four formal project reviews involving the funding body. The agenda and submitted reports were produced by $\mathrm{C}$, with little input from $\mathrm{F}$ or $\mathrm{A} / \mathrm{A}^{*}$. Indeed, the final report included views which were not shared by $\mathrm{A}^{*}$ and F. Nevertheless, the funding body acknowledged the challenges facing the project members and, at the final review, expressed satisfaction with the outputs from all project members.

From an analytical perspective, two of the main structural weaknesses of the project were overall lack of leadership (and hence control) and also a lack of coordination. Informal communications might have provided the channel for mutual alignment, but that was lacking. There was nothing to bridge the two distinct trajectories that emerged (Fig. 6). The lack of leadership would not have been such an issue if there was a functioning co-ordinating mechanism that enabled the researchers to align what they were doing. These weaknesses were reinforced by both the institutional politics and different cultures, the latter evident in terms of the entrenched general views held about the project from a discipline perspective. Nevertheless, whilst each researcher was committed to the project, it was in terms of how it serviced their own specific agendas. Whether much could have been done to improve the cybernetics of the project is open to question, particularly in light of the inability to develop a technology that could be transferred into the IC as was initially intended. When the VSM analysis was presented, it was perhaps too late. Nevertheless, despite the structural dysfunctionality, somehow a coherent message was communicated to the funding body about cohesion - although this was perhaps merely a collective political effort to satisfice the funding body.

\section{Problem Structuring}

The emergence of the two trajectories (Fig. 6) arose despite the clarity of the original project proposal about objectives. One trajectory, reveals a degree of stability, with a clearly defined goal involving actors $\mathrm{C}, \mathrm{D}$ and $\mathrm{E}$. The other was marked by the frustration and uncertainty of actor F. This becomes more clear when the names of the activities are unpacked (Table 4) using the acronym TASCOI (Table 1).

The original proposal concerned both the development of an automated system and its implementation (name 1). Whilst the actors would be C, D, E and F, it would be led by the Investigators, A, B and C. However, with the departure of B and A's delegation to A*, this led to $\mathrm{C}$ assuming a dominant role. The main customer was to be the IC.

The more stable trajectory comprises the activities of the technology development team $(\mathrm{C}$, $\mathrm{D}$ and E). From their perspective, there was not a problem; the project brief prescribed what they should be doing in terms of developing an automated system (name 2). Organisationally, $\mathrm{C}, \mathrm{D}$ and $\mathrm{E}$ operated as a cohesive team. Over time, as their appreciation of the situation matured, the name that they ascribed to what they were doing (name 2: to develop an automated system) drifted to one offering a more generic solution (name 2a: to develop an 'information system'). To add, this shift from name 2 to 2 a did not have any organizational implications. However, there appeared to be disinterest in the system's implementation, whilst, being an added benefit of their work, was not essential to it and did not happen. 
However, the second trajectory (Fig. 6), involving the activities of F, reveals that its named purpose of investigating the organizational - operational implications of a technological implementation (name 3) was problematic. Indeed, for F, this was frustrating and fraught with uncertainty, highlighting the affective aspects of dealing with mess. Over the next fourteen months, this led to activity which involved five iterations of the methodology, oscillating between finding out about the situation (\#1: what is going on?) and trying to establish how to progress (\#5: what can be done?). Despite F's 'problem' being the project group's problem, there was a lack of ownership of the problem by the group in terms of finding a solution. Instead, ownership, in practice and over time, was assumed by F. Moreover, the need for $\mathrm{F}$ to do something resulted in a changed name from name 3 to name $3 n$ (Table 4). The new name had the activity 'to investigate the challenges of conducting a messy multi-disciplinary research project'. In this case the changing of names (\#2) did have organisational implications, with ownership being assumed by $\mathrm{F}$ under name $3 \mathrm{n}$. Under this new name, the actor became researcher $\mathrm{F}$, suppliers would be those involved in any capacity with the project, the owner would be F and the customers would be the audience benefiting from an analysis of the project, hence dissolving the dependency upon the implementation of a system and the other project actors.

\section{Modelling}

One of the outcomes of both \#3 and \#5 is the production of models. As previously mentioned, this notion of a model has been viewed in the broadest of meanings (c.f. Pidd 2003) for the purpose of stimulating debate about suitable and feasible change / improvements.

In the case of $\# 5$, the technical researchers $(C, D$ and $E$ ) were engaging in building a prototype which should have been trialled within the work-place of the IC. C's view of the prototype was captured in the statement:

“Certainly, our proposed system wasn't $100 \%$ perfect... <<the technical problems $>>$ were not insolvable, but which would have required... considerable amount of investment",

adding,

"the sort of money that was involved was too great for the perceived benefits...".

In contrast, the site manager of the IC stated that that aside from the lack of a budget for the investment

"the application was quite possibly too sophisticated and needed too much installation".

Indeed, a technician from the industrial collaborator perhaps captured succinctly the dilemma:

“it was as if what we wanted wasn't a great enough or big enough challenge...”.

Whilst implementation was an issue, the technical development of a prototype proceeded as a lab based exercise. The prototype, as a model, met the requirements of its creators rather than those of its intended beneficiaries. Pragmatic need stood in stark contrast to academic challenge.

If the implementation had proceeded, then $\mathrm{F}$, under the direction of $\mathrm{A} / \mathrm{A}^{*}$, would have used the VSM to examine its impact. Indeed, the site was holistically modelled in much detail, identifying the specifics of activities, roles, responsibilities and organisational developments over time, which were analysed using the VSM. The insight from both the process of collecting data and modelling the site using the 
VSM, proved useful to several people in the IC during F's discussions with them about their roles; it deepened their understanding of what they did and how the site functioned. Nevertheless, F's focus on modelling using the VSM was counter to C's view who believed that IDEF modelling was more appropriate. This conflict was never reconciled and became immaterial in view of the non-implementation.

Meanwhile, F produced a variety of diagrammatical models, these constituting proposals about how to take the project forward, these proposals composed of text and images. These proposals were used in discussions and meetings to secure agreement about research activities. Meetings were informal, involving all participants, though not necessarily all present at the same time. Irrespective, proposals were unchallenged. In the absence of an implementation, no-one had any fixed views about how to proceed, excepting that, from the perspectives of $\mathrm{A} / \mathrm{A}^{*}$, any modelling by $\mathrm{F}$ was to be conducted using the VSM. From F's perspective, it was as if there was a sense of indifference - as long as F was doing something that was justifiable.

Fourteen months into the project (Fig. 4), both the VIPLAN Methodology and the VSM were used to model the project organisation (\#3), approach (\#3) and its topics (\#5). This was described by F:

I give a seminar in the Business School, presenting my approach to my research, using the framework offered by the CM [VIPLAN Methodology] and VSM.

In preparing for this, the project was modelled as a process with its various activities allocated to the six activities. The VIPLAN Methodology highlighted the less obvious issues that were masked by ambiguity and uncertainty, these specifically relating to the organisational context of the project and F's role. Whilst \#2 focused upon names and defining objectives, \#3 focused upon the organisation of the project and its modelling using the VSM (Fig. 5).

...from the perspective of an observer observing the observing system observing the observed system. What is suggested is the ineffectual nature of the regulatory mechanisms originally envisaged.... Since the observer $[\mathrm{F}]$ is part of the observing system, the activity of observing the observing system can be viewed as a self-regulating activity for the project, but only if the mechanisms are in-place for this activity to provide useful feedback to the project management and the management are in a position to modify the project organisation and activities. This, in essence, is the process of "project management".

It became evident that, despite good intentions, the project's organisational conditions were not conducive for effective discussions as to what $\mathrm{F}$ should be doing, with the technical aspects of the project assuming a degree of autonomy, independent of the cohesion of the project. First, there was a lack of coherent direction, drawing attention to the question of who was leading this project. Second, IC's site manager admitted latterly "I think that it is also our own fault, I would say, we could have done a little bit more". The argument presented in the seminar was appreciated and led to endorsement of using the project itself as an object of study. However, since the project itself was moving into its final phase, there was no further action.

In sum, modelling took different forms: an engineering prototype, a diagrammatical research proposal, an organisational activity mapping, with analytical modelling using IDEF and VSM, and a research process modelling, using the VIPLAN Methodology. 


\section{Finale}

The project, despite all its problems, was deemed a success by all. This was possibly due to the commitment of each researcher to their own personal agenda, and that this could be brought together to provide a coherent narrative. More importantly, F found comfort in being able to reconcile what was happening and own role through use of the VIPLAN Methodology, dissolving doubt and becoming confident about what to do. The iterative nature of trying to understand what was going on and the formulation of proposals had led to a shift of focus from a study of a non-existent technology implementation to a study which included the challenges of conducting messy multi-disciplinary research.

\section{Discussion}

This case-study is an example of a project fraught with problems, but also one that demonstrates the utility of the VIPLAN Methodology. The methodology was not used in a workshop situation facilitated by an expert as might be expected with a PSM (Mingers and Rosenhead 2004; Lami and Tavella 2019), but was one that, over time, was 'discovered' and latterly shaped the thinking of one member (F) of a project team in a messy and conflictual situation. For F, it was obvious that a problem had arisen affecting $\mathrm{F}$ due to the absence of the technology implementation. However, this was not recognised by others, especially $\mathrm{C}$. As such, $\mathrm{F}$ had a constant feeling of unease and was not clear how to proceed, in particular, how to refocus the research activity in a meaningful way aligned to the project aims. F's 'discovery' of the VIPLAN Methodology remedied the situation by providing a credible and satisfying explanation about what was happening, enabled a meaningful refocusing of F's research activity and consequently helped $\mathrm{F}$ surmount the unease about the situation.

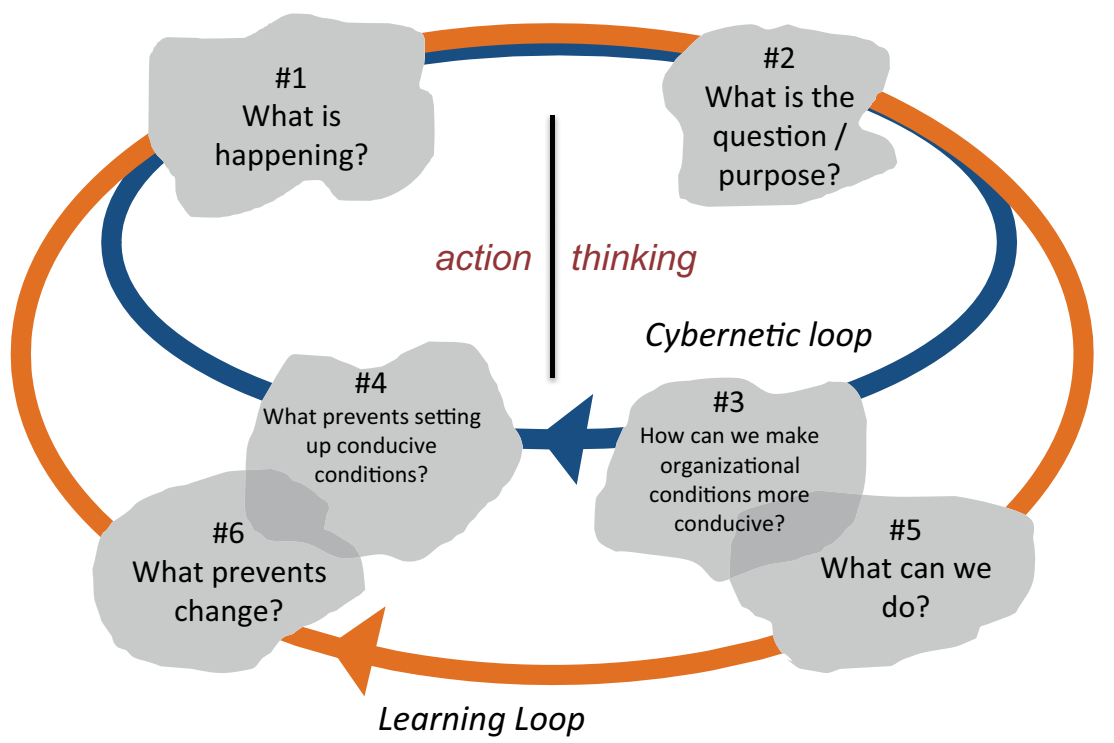

Fig. 7 Asking questions when using the VIPLAN methodology 
The analysis of the case offers the opportunity to reflect over the issues it raises (i.e. we as observers, observing the observing system). Thus, rather than provide a neat explanation of why the use of the VIPLAN Methodology delivered a successful outcome in terms of project recovery, the case-study provides the opportunity to explain some of the challenges in using the VIPLAN Methodology and address some of the questions raised previously and captured in Table 2. This raises nine themes, each with a lesson.

\section{Nine Themes - Lessons}

Theme 1 - Mode of use The VIPLAN Methodology has been developed for application in messy situations. The challenge that faces those dealing with messes is that there is the temptation to 'fumble about', drawing upon intuition and serendipity in the hope that something might turn up to deal with a problem. Alternatively, one might be attracted to prescriptive approaches; if you follow a specified sequence of steps then the desired outcome will result. This assumes that we understand the situation, have established the causal relations constituting the situation and know how we can manipulate causality to generate the desired outcome. However, does this really happen in practice?

The case-study reveals an emergent process, with 'fumbling about' being replaced by the analytic approach offered by the VIPLAN Methodology. Latterly in the project, it afforded guidance about how to make sense of the situation and hence to explain the researcher's predicament and the inability to effect change in a deeper manner than would have been otherwise. In this example, use of the methodology was to explain what was happening, with change being limited to F's activity and wellbeing, rather than this being a collective event. The methodology's strength was in how it highlighted the importance of the cybernetics of the situation, in other words, who were the relevant stakeholders and how they were organised. This shaped what was possible and the effectiveness of any learning and consequent action. This is illustrated with the irreconcilable structural conditions that legitimised the stances of the participants and F's repositioning of what was to be done.

The methodology, in its use, did not prescriptively or mechanically follow the six activities sequentially. Instead, the activities were 'pointers' as to what to do next (Espejo and Reyes 2011). This resonates with Brown's (2008) notion of a 'system of spaces', with a space denoting similar activities. In this view, an inquiry is not something which follows a predictable trajectory, but a path which reveals itself over time revealing an iterative process. The log table was a means to reveal this iterative process. Each time we stop to ponder what to do, we look to pointers to indicate the next stage, in other words, selecting a specific activity as appropriate to the direction needed at that moment. It is performative. This complements the explanatory contribution of the methodology as used in the case-study. Moreover, each activity can be associated with a question that focuses attention upon the expected outcome of the activity (Fig. 7). Thus, depending upon the stage of the inquiry, the appropriate activity is invoked, which reveals flexibility in application. This more intuitive approach aligns with Checkland's (1999) shift from the formality of using the SSM, to a more interactionist approach in which the SSM offers a framework to guide a reflective engagement, with the enquiry process drawing upon the framework as appropriate.

Theme 2 - A temporal dimension This view of activities as pointers and the iterative manner of their use, highlights the importance of time for the emergence of understanding and revision of practice. In the case-study, while making sense of what was involved in the development of 
the automated system invoked one iteration of the methodology, this was not the case for F. As illustrated in Fig. 6, there were a number of iterations, with names identifying different goals and with different organisational consequences. This reflected C's unease about what (s)he was doing. This distinction is apparent in two published cases where only one iteration is evident: Regent Engineering (Bowling and Espejo 1992) and operational change in an SME (Harwood 2012). In contrast, the example of the $\mathrm{PhD}$ experience, as presented in Harwood and Eaves (2018), suggests that the $\mathrm{PhD}$ process might be construed as a succession of ill-defined problem situations invoking a number of iterations, each comprising the six activities as appropriate, as well as their respective specific organisational implications. The example of the design of a research methods course (Harwood 2016) reveals a recursive nature to iterations, with an initial meta-level view of developing an appreciation of the course within the Degree Programme, unfolding down to a sub-level iteration attending to details of the student's learning experience. The challenge in planning the path can be problematic, with it being necessary to unpack the approach into different phases, each with its own challenges that need to be overcome, before moving onto the next phase. The number of iterations reflect the nature of the unfolding of the inquiry.

Theme 3 - Organisational context The case-study is that of a multi-disciplinary research project team, whilst other applications have ranged from a relatively small private company (e.g. Regent Engineering: Bowling and Espejo 1992) to relatively large public sector organisations (e.g. National Audit Office of Colombia: Espejo 2019; Swedish Nuclear Regulators: Espejo and Reyes 2011). It has also been reflectively applied to the experience of a $\mathrm{PhD}$ student (Harwood and Eaves 2018) and proposed as an approach to handle the complexity of Water-Energy-Food Nexus issues (Harwood 2018). This suggests that the notion of organisation is less about a bounded entity designated as an organisation, but about the organisation of agents constituting a hybrid organisation, perhaps drawing from different formal organisations, these constituting organisational systems, as well as independent agents. This invites research into whether the manner of use of the methodology and its challenges are characterised by the type of organisation it is applied to.

Theme 4 - Organising for use The case-study provided little insight into what organisation was desirable for use, as the methodology was used by an individual in a group context, but with informal discussions and meetings as the vehicles for application. Likewise, the published applications of the methodology are equally relatively limited. Nevertheless, the methodology is not confined to use within workshops, but can involve a configuration of informal discussions, interviews, meetings and workshops determined by the specific application. Indeed, this is an area that, as raised by those within Behavioural OR (e.g. Hämäläinen et al. 2013; Franco and Hämäläinen 2016), offers an opportunity for better understanding in order to be more effective in enrolment, modelling and decision making. This becomes particularly important in managing situations in which there are conflicting views raising the challenge of how to get agreement about what to focus upon and do.

Theme 5 - Making sense of the situation (\#1) The starting point is to achieve deep understanding of the situation, which can be achieved by producing rich pictures about the situation (Checkland 1972, 1981). This is a well-documented activity (e.g. Lewis 1992; Bronte-Stewart 1999; Bell and Morse 2013; Bell et al. 2019) with advice suggesting that more explicit rich picture generation can provide a means to surface and share different 
stances. However, the case-study revealed that F's efforts to make sense of the situation in the form of a variety of sketches and shared in informal discussions were not sufficient to overcome deeper rooted personal agendas. This was despite growing appreciations of each other's position. Whilst the case did not provide any new insights into rich pictures, personal experiences, including with students, have revealed the invaluable fresh perspectives that can emerge through the use of rich pictures, affording the opportunity to rethink what might be taken for granted, develop shared mental models of the situation and offer new possible names to deal with the situation.

Theme 6 - Defining the problem (\#2) The translation of the messiness of the situation into a rich picture can be used to establish where to focus attention in the form of names that express the purpose of anticipated action and the organisation that is conducive to make this action effective (\#2). In the case-study, various names were revealed. One (name 1) revealed lack of control over the project's object of study. A second (name 2 , shifting to name 2a) reflected a view that was clearly defined in terms of a shared purpose that guided a sub-group of the researchers to their achievement. A third (name 3) reflected the ill-definition of meaningful purpose for F's subsequent activities, this creating unease for F, but eventually resulting in the meaningful name $3 \mathrm{n}$. What was missing was a name shared by all researchers. However, this makes the assumption there is both a willingness and mechanism to allow such a name to be brought forth. Whilst the VIPLAN Methodology supports the pursuit of a given name, an application of the VIPLAN Methodology need not imply that it supports the 'optimal' needs of all stakeholders, but rather, can be a means for a stakeholder or sub-group of stakeholders to deal with uncertainty. This shifts attention from the use of names to generate group consensus to devices to support individual learning within fragmented groups (Espejo et al. 1996).

In the case of operational change in an SME (Harwood 2012), the name expressed the relatively well-defined goal of production improvement for which there was consensus, with all working towards this goal. In the case of Regent Engineering (Bowling and Espejo 1992), a workshop led to improved relations between two managers despite a personality conflict. In the case-study presented here, there were entrenched views, which, whilst influencing how each was thinking, had little impact in changing the situation.

However, the situations in these three cases are relatively well-defined. The possible challenge arises when the methodology is to be used in more complex situations involving multiple stakeholders at, say, a national level. Espejo and Reyes (2011) reveal the operationalisation of the VIPLAN Methodology at the national level in the case of Swedish Nuclear Regulators, though this appears to have involved relatively few stakeholders. However, it is unclear how the VIPLAN Methodology was operationalised in the case of the National Audit Office of Colombia (Espejo 2019). Moreover, to scale up an application to a situation as characterised by the Water - Energy - Food Nexus (Harwood 2018) involving multiple stakeholders, with possible conflicting interests-agendas and the possible crossing of nation-state boundaries, raises questions about the reality of bringing everyone to an agreement. In view of possible conflicts, can the methodology be used to negotiate the trade-offs that might be required? In irreconcilable situations with fragmentation rather than consensus, as was evident in the narrative of the case-study, a name can support individual learning within these fragmented groups, with the name establishing the purpose to this learning (Espejo et al. 1996). 
Theme 7 - Modelling (\#3/\#5) Modelling is not unilaterally confined to a particular type of model nor exclusively to be viewed as a representation of reality (Espejo 1992). Instead, models can take many forms (Espejo and Reyes 2011). This aligns with Pidd's (2003) elaboration about the different types of models. The prototype of the system developed in the lab, as a working model, demonstrated capability but also offered a focus for conversations about possibilities - in other words it served as an epistemological device (Espejo 1992, 1996), even though the desired goal of transfer into the IC never transpired. Since models can take any form (Espejo and Reyes 2011), then formal mathematical modelling has as much validity in \#5 as the formal conceptual models of Checkland (1981), or any other model. The concern is the support the model gives to decision-making about what to do.

Whilst modelling takes place in a conceptual domain, those operating in the Behavioural OR domain draw attention to the operational context within which modelling takes place. Since it often can be a facilitated group activity, a conducive context is a workshop environment (Mingers and Rosenhead 2004; Franco and Montibeller 2010; Lami and Tavella 2019). Whilst attendees are likely to be identified in \#2, the manner in which the workshop is conducted and the behaviour of attendees, invites questions about the cybernetics of the workshop and the implications for their organisation and regulation (\#3).

Theme 8 - Managing change (\#4/\#6) This is about making things happen, of which there are two aspects. First, is to create conditions (\#4) conducive for the activities of the learning loop,

Table 5 Nine lessons about the use of the VIPLAN Methodology

Theme Lessons

1. Mode of use

2. A temporal dimension

3. Organisational context (system)

4. Organising for use

5. Making sense of the situation (\#1)

6. Defining the problem (\#2)

7. Modelling (\#3/\#5) [thinking]

8. Managing change happen (\#4/\#6) [action]

9. Reflecting over what is happening
Use of the methodology is performative and an emergent process which can be iterative over time. Its six activities are 'pointers' during the inquiry process, implying that the selection of any activity is based upon what direction is needed at any stage in the inquiry process.

Rather than being confined to a workshop activity, the methodology can be used iteratively over a period of time.

Where there is an organisation of entities (i.e. an organisational system), then the methodology can be applied.

This is the configuration of engagements such as informal discussions, interviews, meetings and workshops, which are determined by the specific application. Each form of engagement needs better understanding in terms of how to improve its effectiveness.

Rich pictures provide invaluable fresh perspectives affording the opportunity to rethink what might be taken for granted, develop shared mental models of the situation and offer new possible names to deal with the situation.

The VIPLAN methodology need not support the pursuit of group consensus, but where there is group fragmentation, it can support individual learning within these fragmented groups, with the name giving purpose to this learning (Espejo et al. 1996).

Modelling approaches should be adopted that are deemed useful, either to represent or as a means to elicit views, rather than be dictated by protocol.

Closure need not emerge from problem 'solutions' (i.e. changes in the situation), but can emerge from the removal of doubt or dissatisfaction about the situation through the reconfiguration of how the situation is understood.

The methodology offered a heuristic rather than a formalised problem solving framework (Espejo and Reyes 2011) to think through both design for action and what has happened. 
which is about the cybernetics of the situation. Second, is to manage (\#6) the proposed change emerging from \#5 to give closure.

The conditions conducive to change concern the manner in which different participants are organised, which can be modelled using the VSM (\#3). The nature of this organisation draws upon the names, in particular the organisational name that provides the context for learning. This is illustrated in the case-study with the different names F derived (Table 4). These issue based names reveal different organisational configurations. One (name 3n) dissolved tensions and gave control to F. However, making sense of the cybernetics of the situation and sharing this with others need not transfer over to \#4, thereby allowing the situation to be improved. Knowing what to do is different from making change happen. There must be a willingness for people to participate (\#4) in the dialogue that constitutes the Learning Loop. If this does not happen then the situation remains fragmented and, as mentioned, individual learning takes place within these fragmented groups.

The final activity (\#6) concerns the issue of problem closure, or closure for that iteration. Eden (1987) reveals the Western orientation towards well-structured problems with right answers. However, the indeterminate nature of problem situations (Dewey 1938; Rosenhead 1989) questions this. Whilst Eden (1987) proposes that problems can be 'finished' denoting an act of completion, the notion of 'dissolving' draws attention to closure arising from a change in both intentions and the mental state of dissatisfaction (Ackoff and Emery 1972). This resonates with Peirce's (1873) and Dewey's (1938) view of doubt being a trigger for inquiry. Inquiry stops when doubt is removed (Peirce 1873) or dissatisfaction is dissolved or removed (Ackoff and Emery 1972). Closure need not emerge from problem 'solutions' (i.e. changes in the situation), but can emerge from the removal of doubt or dissatisfaction about the situation through the reconfiguration of how the situation is understood.

Theme 9 - Reflecting over what is happening If one wants to learn from the experience of dealing with a messy situation, then there is likely to be some form of reflection. Likewise, in using the VIPLAN Methodology, how does one assess and learn about how one is using it? In the case-study, F collated details and thoughts of what was happening on an on-going basis in a log table. This, over time, revealed iterations and themes. If one reflects over the complex process of the $\mathrm{PhD}$ conducted by one person, then the different iterations and stages of the $\mathrm{PhD}$ can be mapped to each of the activities. (Harwood and Eaves 2018). Likewise, the mapping of the design of a research methods course in terms of levels of recursion revealed what might be taken for granted (e.g. how conducive are conditions (Cybernetics Loop) for delivery of course?) (Harwood 2016). The VIPLAN methodology offers a heuristic rather than a formalised problem solving framework (Espejo and Reyes 2011) to think through both design for action and what has happened.

\section{Summation}

In summation, the VIPLAN Methodology is an approach to handle the messiness of situations. It contributes to the portfolio of PSMs, as characterised by Smith and Shaw (2019) (see Appendix). It can be used by an individual to handle their own messy situation or facilitate a group' messy situation, either tacitly or explicitly. The case-study illustrates failure in the latter mode of group learning, leading to use in the former mode to enable individual learning. A range of questions were raised following a review of the 
provenance of the VIPLAN Methodology, which were thematically organised and provided the format for this discussions. This has revealed nine lessons each relating to a theme, which are outlined in Table 5.

\section{Implications}

The focus of the VIPLAN Methodology on context highlights the localised nature of dealing with problem situations and the need to understand the context(s) relevant to concerns. This context shapes how meaning emerges in conversations (Miller and Charles 1991). This suggests that prescriptive generic solutions to problems are misplaced. Instead, approaches to messy situations can be contextually shaped in a performative manner as enabled with the VIPLAN Methodology. However, a number of issues are raised, which have been partially addressed in this paper. First, the methodology can be viewed by the practitioner-user as complex, with confusing terminology. This invites questions about the utility of the nine lessons, the issues each lesson raises and how usage can be better understood. This is particularly relevant to interventionist approaches such as in action research and how the methodology can inform these (Eden and Ackermann 2018; Harwood and Eaves 2018). Second, whilst the methodology is grounded conceptually in Cybernetics and the SSM, Behavioural OR and other approaches for addressing messy situations (e.g. design thinking) invite questions about how these can inform the methodology. Third, discourse to bring forth multi-stakeholder views are important in policy decisions, especially in situations characterised by different and potentially conflicting views. However, when discourse is not possible, the methodology is offered as an explanatory device to support individual learning. Nevertheless, this invites the question of how the methodology can be informed to better handle conflictual situations.

\section{Conclusion}

The VIPLAN Methodology offers an approach for the handling of messy situations. Further, it offers an additional approach to the portfolio that constitute the family of PSMs. Its advantage over these other approaches is that it focuses explicit attention upon the contextual aspects of the problem situation and how this context can be shaped to produce conditions more conducive for handling the situation. However, a major drawback of the limited publications giving account of the VIPLAN Methodology is the lack of detail about how the methodology can be operationalized.

In response, a case-study has been used to explore the operationalisation of the VIPLAN Methodology. This reveals nine lessons. The six activities of the methodology are presented as 'pointers' to different aspects of the inquiry process, thus providing flexibility and invoking that the methodology's use is in a performative manner. Depending on the nature of the inquiry, its use can involve a number of iterations, these reflecting the uniquely problematic nature of different facets of an inquiry. The methodology accommodates any form of modelling, whether quantitative or qualitative, and transcends debates about the incommensurability of mixing methods. Its use is for dealing with problem situations by using conceptualisations of both the situation and the specified problem. Closure is less about the action taken, but instead, is about how dissatisfaction with the situation is eased. We conclude that the VIPLAN Methodology 
provides a useful approach for the handling of messy situations due to its explicit attention to the organisational aspects of such situations, this shaping how any problem situation is defined and can be handled, with its consequent outcomes.

Data Availability Not applicable.

\section{Compliance with Ethical Standards}

Conflicts of Interest/Competing Interests Not applicable

Code availability Not applicable

\section{Appendix}

In answer to any questions about whether the VIPLAN Methodology is a PSM, the criteria offered by Rosenhead (1989) and Smith and Shaw (2019) are used to evaluate the VIPLAN Methodology. With regard to the latter, the responses are similar to those presented by Harwood (2019) in its explanation of why the VSM is a PSM. This is to be expected, since the VIPLAN Methodology is an approach within which the VSM can be applied.

Rosenhead (1989) VIPLAN Methodology response

\section{Characteristics for an alternative paradigm}

Non-optimising; seeks alternative solutions which are acceptable on separate dimensions without trade-offs.

Reduced data demands, achieved by greater integration of hard and soft data with social judgements.

Simplicity and transparency, aimed at clarifying the terms of conflict.

Conceptualizes people as active subjects.

Facilitates planning from the bottom-up.

Accepts uncertainty, and aims to keep options open for later resolution.
Yes: the aim is to find satisficing solutions (March and Simon 1958), recognising that an optimal solution may not be feasible since, what may be optimal for one person may be even more problematic to another. This leads to finding ways to dealing with these messes so that, in principle, all stakeholders are satisfied with its handling

Yes: often there is incomplete information about the situation, in which case there is a need to make do and use judgement to make decisions using the data that is available.

Yes: the approach aims to reveal and make clear the complexity of the experienced situation, revealing the disparate views of those with an interest in the situation.

Yes: people are expected to proactively express their views and engage in dialogue about how to progress.

Yes: the modelling is associated specifically with \#3 if conducted using the VSM. The VSM allows the distribution of discretion (and hence planning) in an organisation to be mapped out recursively, this revealing both the contribution of actors and opportunities to be recognised.

Yes: the starting point is an awareness that something is wrong and uncertainty about what needs to be addressed. The situation is likely to be fluid over time with issues emerging then dissolving depending upon the intervention, to be replaced by other issues. 
Q1: Does the approach identify a system to model?

Q2: Does the approach model participants' subjective interpretations of the world?

Q3: Does the approach seek to build a holistic understanding of the system?

Q4: Does the approach build a qualitative model?

Q5: Does the model building involve the facilitation of participants?

Q6: Does the model building enhance participants' learning about the situation?

Q7: Does the approach aim to develop buy-in to politically feasible outcomes?

Q8: Is credibility established in models by preserving multiple participant contributions?

Q9: Is the model building process suitably generic so it can be transferred to multiple problem contexts?

Q10: Does the model building process aim to create confidence in the outcome through procedural rationality?

Q11: Does the model act as an audit trail of the decision making process validated through collaborative enquiry?

Q12: Does the approach structure knowledge through different stages of analyses?

Q13: Does the approach have distinct phases for divergent and convergent thinking?
Yes: the focus of \#2 is to establish both the organisational system that provides context as well as the activity system that constitutes the issues that are of concern within this organisational system.

Yes: second order cybernetics recognises that we are all observers of each other and ourselves and as such we each have our own view of what we perceive. A subject-subject relationship is an inherent feature of this approach.

Yes: the naming process (\#2) is systemic, drawing upon a rich picture (\#1) that reveals the complexity of the system. The subsequent modelling of the cybernetics (\#3) of the named problem calls upon the VSM, which Smith \& Shaw recognise as being systemic. Other models (quantitative or qualitative) can be used as appropriate.

Yes: \#3 is likely to be a qualitative model using the VSM. \#5 can be both qualitative and quantitative, the latter being numerical models of the situation, as perhaps in a simulation.

Yes: the modelling activities of \#3 and \#5 can be conducted in both a facilitated and an unfacilitated mode, depending upon the expertise required and the manner in which the methodology is being used. The VSM offers a means to elicit views about the complexity of how a situation is organised, though can be used by an expert to make sense of these views (Harwood 2019)

Yes: through the process of model building the model can act as a boundary object (Star and Griesemer 1989; Harwood 2019), enabling the sharing of views and the establishing of a shared mental model.

Yes: the aim is to engage with and elicit views of different stakeholders in such a way to bridge (political) differences, share understandings and find a means for feasible action

Yes: drawing upon Harwood (2019), it is a question of how views are incorporated into models and how models are used. As a boundary object then it would be expected that views contribute to model building.

Yes: the VIPLAN Methodology has been applied to different contexts as illustrated in its review.

Yes: as indicated in Harwood (2019) there is a logical process underpinning model building when using the VSM, which takes the form of both the VIPLAN method and the VIPLAN Methodology, both involving participants.

Yes: any model should be auditable in terms of the source of the data used and how processed by participating stakeholders.

Yes: the VIPLAN Methodology comprises different stages of analysis, which can be conducted in an iterative manner.

Yes: divergent thinking is encouraged in the surfacing of views about the situation. Convergent thinking ideally emerges when there is agreement about what the problem is and how to address it. 
Open Access This article is licensed under a Creative Commons Attribution 4.0 International License, which permits use, sharing, adaptation, distribution and reproduction in any medium or format, as long as you give appropriate credit to the original author(s) and the source, provide a link to the Creative Commons licence, and indicate if changes were made. The images or other third party material in this article are included in the article's Creative Commons licence, unless indicated otherwise in a credit line to the material. If material is not included in the article's Creative Commons licence and your intended use is not permitted by statutory regulation or exceeds the permitted use, you will need to obtain permission directly from the copyright holder. To view a copy of this licence, visit http://creativecommons.org/licenses/by/4.0/.

\section{References}

Ackermann F (2012) Problem structuring methods 'in the dock': arguing the case for soft. OR Eur J Oper Res 219(3):652-658. https://doi.org/10.1016/j.ejor.2011.11.014

Ackoff RL (1974) Redesigning the future. Wiley, New York

Ackoff RL, Emery FE (1972) On purposeful systems. Intersystems Publications, Seaside, California

Ahern T, Leavy B, Byrne PJ (2014) Complex project management as complex problem solving: A distributed knowledge management perspective. Int J Proj Manag 32(8):1371-1381.

Beer S (1972) Brain of the firm. Harmondsworth, Allen Lane, The Penguin Press

Beer S (1979) The heart of Enterprise. Wiley, Chichester

Beer S (1984) The viable system model: its provenance, development, methodology and pathology. J Oper Res Soc 35(1):7-25. https://doi.org/10.1057/jors.1984.2

Beer S (1985) Diagnosing the system for organisations. Wiley, Chichester

Bell S, Morse S (2013) How people use rich pictures to help them think and act. Syst Pract Action Res 26(4): 331-348. https://doi.org/10.1007/s11213-012-9236-x

Bell S, Berg T, Morse S (2019) Towards an understanding of rich picture interpretation. Syst Pract Action Res 32(6):601-614. https://doi.org/10.1007/s11213-018-9476-5

Bowling D, Espejo R (1992) An intervention with the cybernetic methodology in regent engineering. Trans Inst Meas Control 14(1):17-28

Bowling D, Espejo R (2000) Exploring computer supported cooperative work in a retail bank. In: Allen J, Wilby J (eds) ISSS 2000 International Society for the Systems Sciences: accession number 20151. CD-ROM, Toronto

Bronte-Stewart M (1999) Regarding rich pictures as tools for communication in information systems development. Computing and Information Systems 6:85-104

Brown T (2008) Design thinking. Harv Bus Rev 86(6):84-92

Buchanan R (1992) Wicked problems in design thinking. Des Issues 8:5-21. https://doi.org/10.2307/590553

Buchner A (1995) Basic topics and approaches to the study of complex decision making. In: Frensch, PA, Funke, $\mathrm{J}$ (eds) Complex decision making: the European perspective, Lawrence Erlbaum Associates Inc., New Jersey, pp27-63

Checkland P (1972) Towards a systems-based methodology for real-world problem solving. J Syst Eng 3(2):87116

Checkland P (1981) Systems thinking, systems practice. Wiley, Chichester

Checkland P and Scholes J (1990) Soft systems methodology in action. John Wiley \& Sons, Chichester.

Checkland P (1999) Soft systems methodology: a 30-year retrospective. Wiley, Chichester

Churchman CW (1967) Guest editorial, wicked problems. Manag Sci 14(4):B141-B142

Conklin J (2006) Wicked problems \& social complexity. CogNexus Institute, San Francisco

Dewey J (1938) Logic: the theory of inquiry. Henry Holt \& Company, New York

Dringenberg E, Purzer S (2018) Experiences of first-year engineering students working on ill-structured problems in teams. J Eng Educ 107(3):442-467. https://doi.org/10.1002/jee.20220

Duncker K, Lees LS (1945) On problem-solving Psychological Monographs 58(5):i-112. https://doi.org/10.1037 /h0093599

Eden C (1987) Problem solving or problem finishing. In: Jackson MC, Keys P (eds) New directions in management science. Gower Publishing Company, Aldershot, pp97-107

Eden C (1988) Cognitive mapping: a review. Eur J Oper Res 36(1):1-13. https://doi.org/10.1016/0377-2217(88 )90002-1

Eden C (1994) Cognitive mapping and problem structuring for system dynamics model building. Syst Dyn Rev 10(2-3):257-276. https://doi.org/10.1002/sdr.4260100212 
Eden C, Ackermann F (2001) SODA - the principles. In: Rosenhead J, Mingers J (eds) Rational analysis for a problematic world revisited. Wiley, Chichester, pp 21-41

Eden C, Ackermann F (2018) Theory into practice, practice to theory: action research in method development. Eur J Oper Res 271(3):1145-1155. https://doi.org/10.1016/j.ejor.2018.05.061

Espejo R (1988) Cybernetic methodology to study and design human activities dissertation. University in Birmingham, Aston

Espejo R (1990) Complexity and change: reflections upon the cybernetic intervention in Chile, 1970-1973. Syst Pract 3(3):303-313. https://doi.org/10.1007/BF01062734

Espejo R (1991) Action and structure in problem solving. In: Blackham RB, Flood RL, Jackson MC, Mansell GJ, Probert SVE (eds) Systems thinking in Europe. Plenum Press, New York, pp29-41

Espejo R (1992) Management of complexity in problem solving. Trans Inst Meas Control 14(1):8-16. https://doi. org/10.1177/014233129201400103

Espejo R (1996) Requirements for effective participation in self-constructed organizations. Eur Manag J 14(4): 414 422. https://doi.org/10.1016/0263-2373(96)00029-1

Espejo R (2010) Private communication, 29th January 2010

Espejo R (2011a) Private communication, 25th April, 2011

Espejo R (2011b) Seeing a case study through a cybernetic epistemological lens. Kybernetes 40(9-10):12731296. https://doi.org/10.1108/03684921111169387

Espejo R (2015a) Performance for viability: complexity and variety management. Kybernetes 44(6-7):10201029. https://doi.org/10.1080/01605682.2018.1442131

Espejo R (2015b) An enterprise complexity model: variety engineering and dynamic capabilities. Int J Syst Soc 2(1):1-22. https://doi.org/10.4018/ijss.2015010101

Espejo R (2019) Private communication, 11th Feb 2019

Espejo R, Harnden RJ (1989) The viable system model: interpretations and applications of Stafford Beer's VSM. Wiley, Chichester

Espejo R, Reyes A (2011) Organizational Systems: Managing complexity with the viable system model. Springer Science \& Business Media

Espejo R, Schuhmann W, Schwaninger M, Bilello U (1996) Organizational transformation and learning. Wiley, Chichester

Espejo R, Bowling D, Hoverstadt P (1999) The viable system model and the Viplan software. Kybernetes 28(67):661-678. https://doi.org/10.1108/03684929910282944

Franco LA, Greiffenhagen C (2018) Making OR practice visible: using ethnomethodology to analyse facilitated modelling workshops. Eur J Oper Res 265(2):673-684. https://doi.org/10.1016/j.ejor.2017.08.016

Franco LA, Hämäläinen RP (2016) Behavioural operational research: returning to the roots of the OR profession. Eur J Oper Res 249(3):791-795. https://doi.org/10.1016/j.ejor.2015.10.034

Franco LA, Montibeller G (2010) Facilitated modelling in operational research. Eur J Oper Res 205(3):489-500. https://doi.org/10.1016/j.ejor.2009.09.030

Frensch PA, Funke J (1995) Definitions, traditions, and a general framework for understanding complex problem solving. In: Frensch PA, Funke J (eds) Complex decision making: the European perspective, Lawrence Erlbaum Associates, Inc, New Jersey, pp3-25

Friend J (1989) The strategic choice approach. In: Rosenhead J (ed) Rational analysis for a problematic world. Wiley, London, pp 21-157

Friend JK, Hickling A (1987) Planning under pressure: the strategic choice approach. Pergamon Press, Oxford

Getzels JW (1975) Problem-finding and the inventiveness of solutions. J Creat Behav 9(91):12-18. https://doi. org/10.1002/j.2162-6057.1975.tb00552.x

Getzels JW (1979) Problem finding: a theoretical note. Cogn Sci 3(2):167-172. https://doi.org/10.1207 /s15516709 $\operatorname{cog} 0302 \_4$

Goel V, Pirolli P (1992) The structure of design problem spaces. Cognitive Science 16, 395-429.

Hämäläinen RP, Luoma J, Saarinen E (2013) On the importance of behavioral operational research: the case of understanding and communicating about dynamic systems. Eur J Oper Res 228(3):623-634. https://oi. org/10.1016/j.ejor.2013.02.001

Harwood SA (2011) Can a cybernetic lens contribute to the business strategy domain? Kybernetes 40(3-4):507527. https://doi.org/10.1108/03684921111133719

Harwood SA (2012) The management of change and the VIPLAN methodology in practice. J Oper Res Soc 63(6):748-761. https://doi.org/10.1057/jors.2011.73

Harwood SA (2016) The VIPLAN methodology in management research. In: Benson V, Filippaios F (eds) Proceedings of the 15th European conference on research methodology for business and management studies. Academic Conferences and International Publishing Limited, Reading, pp117-125 
Harwood SA (2018) In search of a (WEF) nexus approach. Environ Sci Pol 83:79-85. https://doi.org/10.1016/j. envsci.2018.01.020

Harwood SA (2019) A question of interpretation: the viable system model (VSM). Eur J Oper Res 274(3):11981201. https://doi.org/10.1016/j.ejor.2018.10.054

Harwood SA, Eaves S (2018) Mind the Gap: But does the gap matter in social science research? In: Demartini P, Marchiori M (eds) Proceedings of the 17th European conference on research methodology for business and management studies. Academic Conferences and International Publishing Limited, Reading, pp 163-171

Johnson MP, Midgley G, Chichirau G (2018) Emerging trends and new frontiers in community operational research. Eur J Oper Res 268(3):1178-1191. https://doi.org/10.1016/j.ejor.2017.11.032

Jonassen DH (1997) Instructional design models for well-structured and ill-structured problem-solving learning outcomes. Educ Technol Res Dev 45(1):65-94. https://doi.org/10.1007/BF02299613

Jonassen DH (2000) Toward a design theory of problem solving. Educ Technol Res Dev 48(4):63-85. https://doi.org/10.1007/BF02300500

Kaye PH, Smith AD, Strudwick MJ, White M, Bird CE, Aggarwal G, Durkin T, Marcuson TA, Masters TR, Regan N, Restrepo S, Toller JR, White S, Wilkinson R (2020) Managing uncertainty: principles for improved decision making. Br Actuar J 25(315):1-51. https://doi.org/10.1017/S135732172000015X

Kim DH (1993) A framework and methodology for linking individual and organizational learning: applications in TQM and product development. Dissertation, Massachusetts Institute of Technology, Cambridge, Massachusetts

Kofman F (1992) Lecture slides. MIT Sloan School of Management, Cambridge

Kolko J (2015) Design thinking comes of age. Harv Bus Rev 93(9):66-71

Kunc M, Malpass J, White L (eds) (2016) Behavioral operational research: theory, methodology and practice. Palgrave Macmillan, London

Lami IM, Tavella E (2019) On the usefulness of soft OR models in decision making: a comparison of problem structuring methods supported and self-organized workshops. Eur J Oper Res 275(3):1020-1036. https://doi. org/10.1016/j.ejor.2018.12.016

Levinthal DA, March JG (1993) The myopia of learning. Strateg Manag J 14(S2):95-112. https://doi. org/10.1002/smj.4250141009

Lewis PJ (1992) Rich picture building in the soft systems methodology. Eur J Oper Res 1(5):351-360. https://doi.org/10.1057/ejis.1992.7

March JG, Simon HA (1958) Organizations. Wiley, New York

McDonald JK, Yanchar SC (2020) Towards a view of originary theory in instructional design. Educ Technol Res Dev 68:633-651. https://doi.org/10.1007/s11423-019-09734-8

Micheli P, Wilner SJ, Bhatti SH, Mura M, Beverland MB (2019) Doing design thinking: conceptual review, synthesis, and research agenda. J Prod Innov Manag 36(2):124-148. https://doi.org/10.1111/jpim.12466

Midgley G, Cavana RY, Brocklesby J, Foote JL, Wood DR, Ahuriri-Driscoll A (2013) Towards a new framework for evaluating systemic problem structuring methods. Eur J Oper Res 229(1):143-154

Mikkelsen MF (2020) The complex project complexity-identification of five ideal research types. J Mod Proj Manag 7(4):1-24. https://oi.org/10.19255/JMPM02201

Miller GA, Charles WG (1991) Contextual correlates of semantic similarity. Lang Cognitive Proc 6(1):1-28. https://doi.org/10.1080/01690969108406936

Mingers J, Rosenhead J (2004) Problem structuring methods in action. Eur J Oper Res 152(3):530-554. https://doi.org/10.1016/S0377-2217(03)00056-0

Mingers J, White L (2010) A review of the recent contribution of systems thinking to operational research and management science. Eur J Oper Res 207(3):1147-1161. https://doi.org/10.1016/j.ejor.2009.12.019

Morrill N (2007) Are the benefits of PSMs being sold sufficiently? A practitioner's view. J Oper Res Soc 58(5): 686-689. https://doi.org/10.1057/palgrave.jors.2602375

Munro I, Mingers J (2002) The use of multimethodology in practice - results of a survey of practitioners. J Oper Res Soc 53(4):369-378. https://doi.org/10.1057/palgrave.jors.2601331

Nadin S, Cassell C (2006) The use of a research diary as a tool for reflexive practice. Qual Res Account Manag 3(3):208-217. https://doi.org/10.1108/11766090610705407

Newell A, Shaw JC, Simon HA (1958) Elements of a theory of human problem solving. Psychol Rev 65(3):151

Newell A, Simon HA (1972) Human problem solving. Prentice-Hall Inc, New Jersey

Paucar-Caceres A, Jerardino-Wiesenborn B (2020) A bridge for two views: Checkland's soft systems methodology and Maturana's ontology of the observer. J Oper Res Soc 71(4):60-672. https://doi.org/10.1080 /01605682.2019.1578629

Peirce CS (1873) The logic of 1873 collected papers Vol 7, science and philosophy (1958). Harvard University Press, Cambridge

Peirce CS (1903) Pragmatism and abduction in collected papers Vol 5, pragmatism and Pragmaticism (1934). Harvard University Press, Cambridge 
Perko I, Espejo R (2017) Big data analytics Organisational learning. Рефлексивные процессы и управление, Сборник материалов XI Международного симпозиума. 16-17октября 2017г., Москва

Pidd M (2003) Tools for thinking: modelling in management science. Wiley, Chichester

Ramírez-Gutiérrez AG, Cardoso-Castro PP, Tejeida-Padilla R (2020) A methodological proposal for the complementarity of the SSM and the VSM for the analysis of viability in organizations. Syst Pract Action Res in press https://doi.org/10.1007/s11213-020-09536-7

Ranyard JC (1995) Supporting real decisions: a review of OR practice in the UK. Eur J Oper Res 87(3):474-482. https://doi.org/10.1016/0377-2217(95)00223-5

Reyes A (2001) Second-order auditing practices. Syst Pract Action Res 14(2):157-180. https://doi.org/10.1023 /A:1011355721951

Rittel HWJ, Webber MM (1973) Dilemmas in a general theory of planning. Policy Sci 4:155-169. https://doi. org/10.1007/BF01405730

Rosenhead J (1989) Introduction: old and new paradigms of analysis. In: Rosenhead J (ed) Rational analysis for a problematic world: problem structuring methods for complexity, uncertainty and conflict, Wiley, Chichester, pp $1-20$

Simon HA, Newell A (1958) Heuristic problem solving: the next advance in operations research. Oper Res 6(1): 1-10. https://doi.org/10.1287/opre.6.1.1

Smith CM, Shaw D (2019) The characteristics of problem structuring methods: a literature review. Eur J Oper Res 274(2):403-416. https://doi.org/10.1016/j.ejor.2018.05.003

Snowden D (2002) Complex acts of knowing: paradox and descriptive self-awareness. J Knowl Manag 6(2): 100-111. https://doi.org/10.1108/13673270210424639

Stadler M, Fischer F, Greiff S (2019) Taking a closer look: an exploratory analysis of successful and unsuccessful strategy use in complex problems. Front Psychol 10:777. https://doi.org/10.3389/fpsyg.2019.00777

Urdaneta RZ (2001) Creating a New Auditor at the Contraloría General de la República de Colombia (CGR). Syst Pract Action Res 14(2):181-202. https://doi.org/10.1023/A:1011307806022

Von Foester H (1979) Cybernetics of cybernetics. In: Krippendorff, K (ed) Communications and control in society, Gordon \& Breach, New York, pp5-8

Watson CE (1976) The problems of problem solving. Bus Horiz 19(4):88-94

White L, Kunc M, Burger K, Malpass J (eds) (2020) Behavioral operational research: a capabilities approach. Palgave Macmillan, Cham

Wilson B (1984) Systems: concepts, methodologies and applications. Wiley, Chichester

Wolff K (2020) Researching the engineering theory-practice divide in industrial problem solving. Eur J Eng Educ 45(2):181-195. https://doi.org/10.1080/03043797.2018.1516738

Zadeh LA (1965) Fuzzy sets. Inf Control 8:99-102

Kolb DA (1981) Learning styles and disciplinary differences. In: Chickering AW and Associates (eds) The modern american college: responding to the new realities of diverse students and a changing society. Jossey Bass Higher \& Adult Education Series, San Francisco, pp 232-255

Star SL, Griesemer JR (1989) Institutional ecology, translations' and boundary objects: Amateurs and professionals in Berkeley's Museum of vertebrate zoology, 1907-39. Social Studies of Science 19(3):387-420

Publisher's Note Springer Nature remains neutral with regard to jurisdictional claims in published maps and institutional affiliations. 